Florida International University

FIU Digital Commons

FIU Electronic Theses and Dissertations

University Graduate School

6-23-2014

\title{
Time Trends and Predictors of Initiation for Cigarette and Waterpipe Smoking Among Jordanian School Children: Irbid, 2008-2011
}

Karma L. McKelvey PhD

Florida International University, kscot005@fiu.edu

DOI: $10.25148 /$ etd.FI14071118

Follow this and additional works at: https:// digitalcommons.fiu.edu/etd

Part of the Epidemiology Commons, and the Longitudinal Data Analysis and Time Series Commons

\section{Recommended Citation}

McKelvey, Karma L. PhD, "Time Trends and Predictors of Initiation for Cigarette and Waterpipe Smoking Among Jordanian School Children: Irbid, 2008-2011" (2014). FIU Electronic Theses and Dissertations. 1420.

https://digitalcommons.fiu.edu/etd/1420

This work is brought to you for free and open access by the University Graduate School at FIU Digital Commons. It has been accepted for inclusion in FIU Electronic Theses and Dissertations by an authorized administrator of FIU Digital Commons. For more information, please contact dcc@fiu.edu. 


\title{
FLORIDA INTERNATIONAL UNIVERSITY
}

Miami, Florida

\section{TIME TRENDS AND PREDICTORS OF INITIATION FOR CIGARETTE AND WATERPIPE SMOKING AMONG JORDANIAN SCHOOL CHILDREN: IRBID, 2008-2011}

\author{
A dissertation submitted in partial fulfillment of the \\ requirements for the degree of \\ DOCTOR OF PHILOSOPHY \\ in
}

PUBLIC HEALTH

by

Karma McKelvey

2014 


\section{To: $\quad$ Dean Michele Ciccazzo}

Robert Stempel College of Public Health and Social Work

This dissertation, written by Karma McKelvey, and titled Time Trends and Predictors of Initiation for Cigarette and Waterpipe Smoking among Jordanian School Children: Irbid, 20082011, having been approved in respect to style and intellectual content, is referred to you for judgment.

We have read this dissertation and recommend that it be approved.

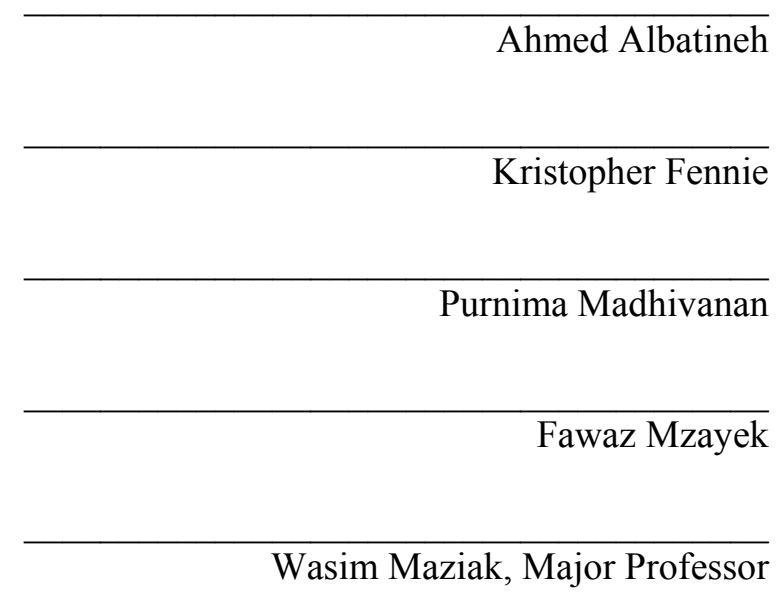

Date of Defense: June 23, 2014

The dissertation of Karma McKelvey is approved.

Dean Michele Ciccazzo

Robert Stempel College of Public Health and Social Work

Dean Lakshmi N. Reddi University Graduate School

Florida International University, 2014 


\section{DEDICATION}

To my family, friends, mentors, committee members, coauthors, and the Universe at large. Thank you for conspiring to help me achieve my lifelong dream. 


\section{ACKNOWLEDGMENTS}

Drs. Wasim Maziak, Purnima Madhivanan, Fawaz Mzayek, Kristopher Fennie, Mary-Jo Trepka, and Jennifer Attonito. Ladies of D7. Michelle Causey, Michele Wilmath, Joy Hobbs, Barbara Winter, Dawn Eddlestein, Patti Gray, Jeff Scott. Without whom, at any given time, this would not have been possible.

This dissertation was supported by the National Institute on Drug Abuse (NIDA) (grants R01 DA024876 and R01 DA035160). 


\title{
ABSTRACT OF THE DISSERTATION
}

TIME TRENDS AND PREDICTORS OF INITIATION FOR CIGARETTE AND WATERPIPE SMOKING AMONG JORDANIAN SCHOOL CHILDREN: IRBID, 2008-2011

\author{
by \\ Karma McKelvey \\ Florida International University, 2014 \\ Miami, Florida \\ Professor Wasim Maziak, Major Professor
}

Smoking prevalence among adolescents in the Middle East remains high while rates of smoking have been declining among adolescents elsewhere. The aims of this research were to (1) describe patterns of cigarette and waterpipe (WP) smoking, (2) identify determinants of WP smoking initiation, and (3) identify determinants of cigarette smoking initiation in a cohort of Jordanian school children.

Among this cohort of school children in Irbid, Jordan, (age $\approx 12.6$ at baseline) the first $\operatorname{aim}(\mathrm{N}=1,781)$ described time trends in smoking behavior, age at initiation, and changes in frequency of smoking from 2008-2011 (grades 7 - 10). The second aim $(\mathrm{N}=1,243)$ identified determinants of WP initiation among WP-naïve students; and the third aim $(\mathrm{N}=1,454)$ identified determinants of cigarette smoking initiation among cigarette naïve participants. Determinants of initiation were assessed with generalized mixed models. All analyses were stratified by gender.

Baseline prevalence of current smoking (cigarettes or WP) for boys and girls was $22.9 \%$ and $8.7 \%$ respectively. Prevalence of ever- and current- any smoking, cigarette smoking, WP smoking, and dual cigarette/WP smoking was higher in boys than girls each year $(\mathrm{p}<0.001)$. At all time points, prevalence of WP smoking was higher than that of cigarette smoking $(p<0.001)$ for both boys and girls. WP initiation was documented in 39\% of boys and $28 \%$ of girls. Cigarette initiation was documented in $37 \%$ of boys and $24 \%$ of girls. Determinants of WP 
initiation included ever-cigarette smoking, low WP refusal self-efficacy, intention to smoke, and having teachers and friends who smoke WP. Determinants of cigarette smoking initiation included ever-WP smoking, low cigarette refusal self-efficacy, intention to start smoking cigarettes, and having friends and family who smoke.

These studies reveal intensive smoking patterns at early ages among Jordanian youth in Irbid, characterized by a predominance of WP smoking. WP may be a vehicle for tobacco dependence and subsequent cigarette uptake. The sizeable incidence of WP and cigarette initiation among students of both sexes points to a need for culturally relevant smoking prevention interventions. Gender-specific factors, refusal skills, and smoking cessation of both WP and cigarettes for youth and their parents/teachers would be important components of such initiatives. 


\section{TABLE OF CONTENTS}

\section{CHAPTER}

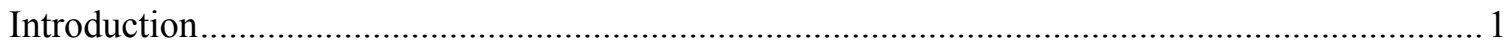

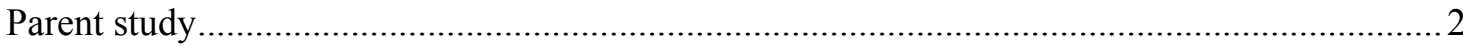

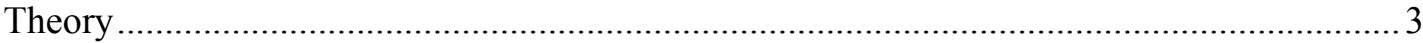

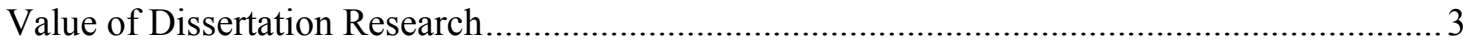

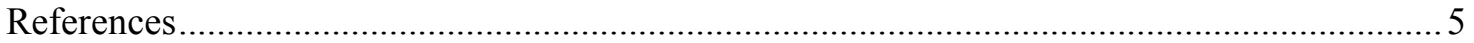

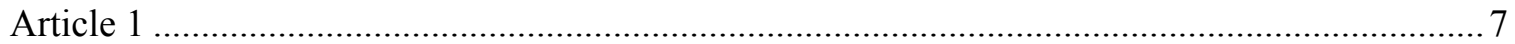

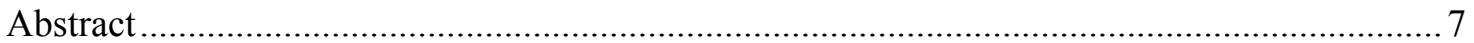

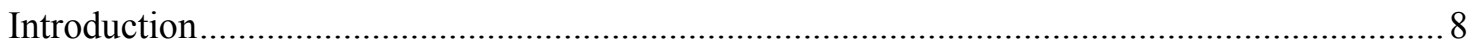

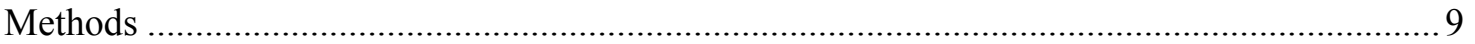

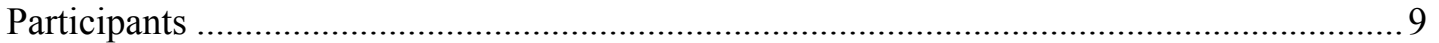

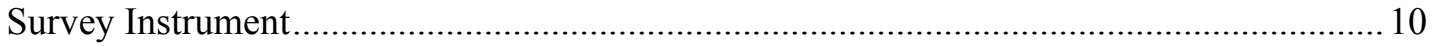

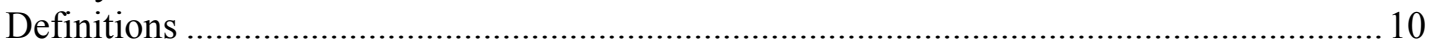

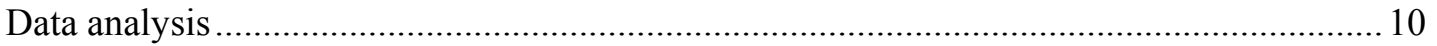

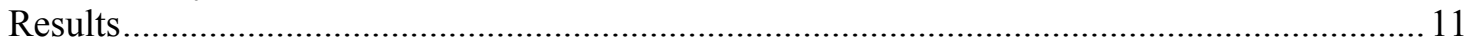

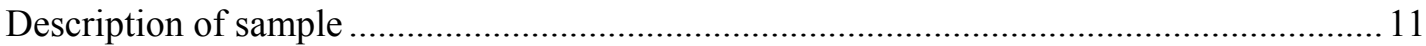

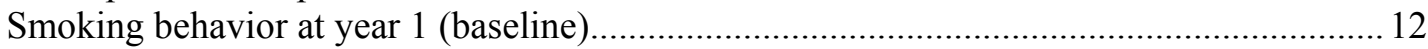

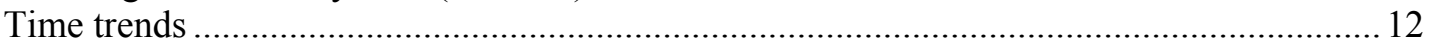

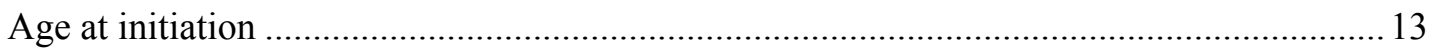

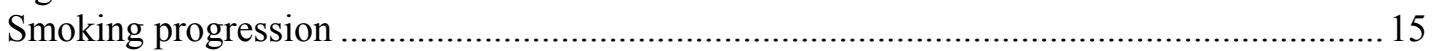

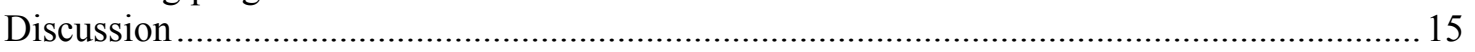

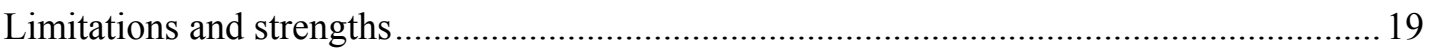

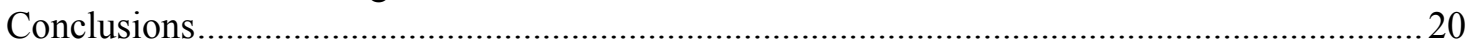

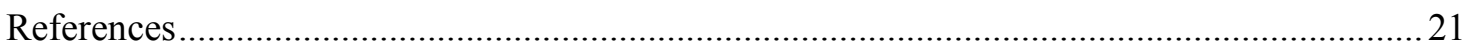

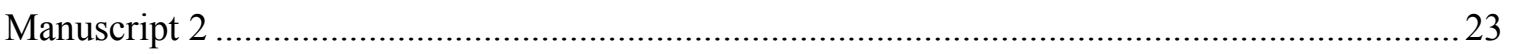

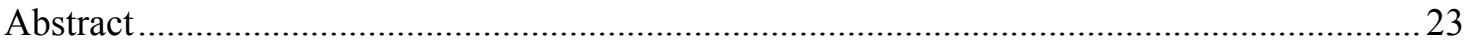

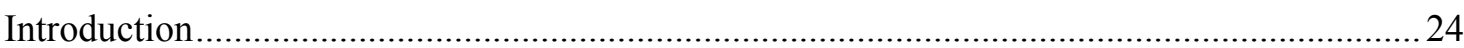

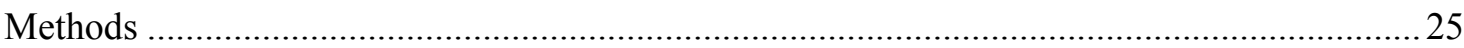

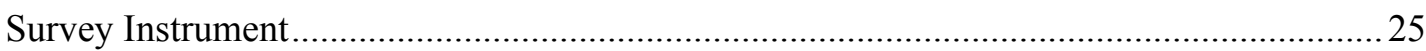

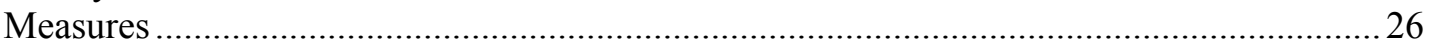

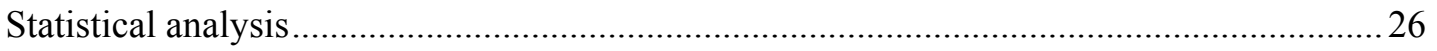

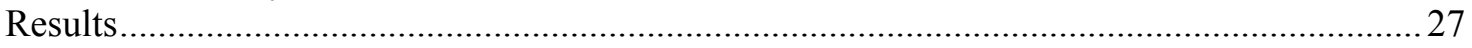

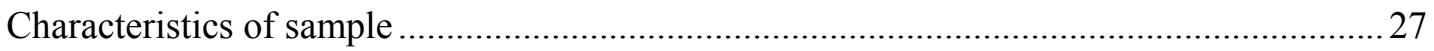

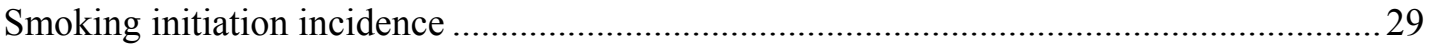

Association of ASE variables and WP smoking initiation by tenth grade.............................29

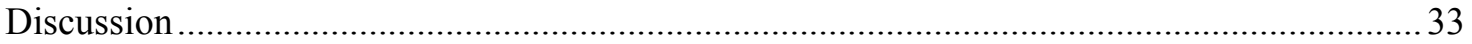

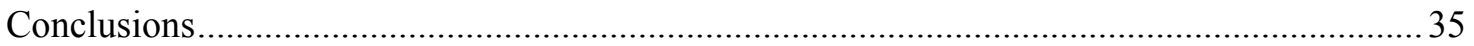

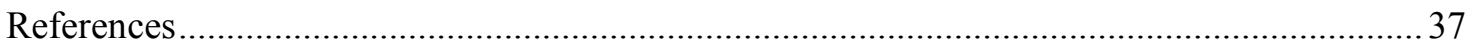

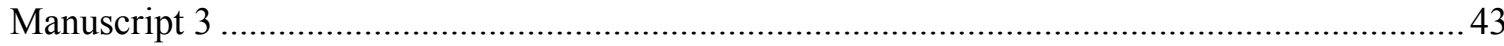

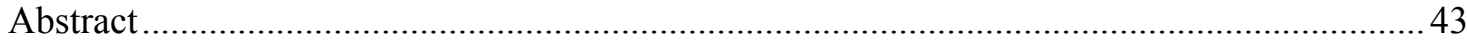

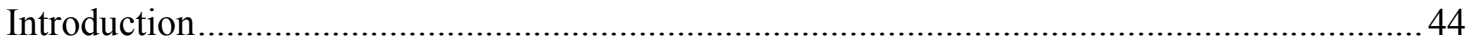

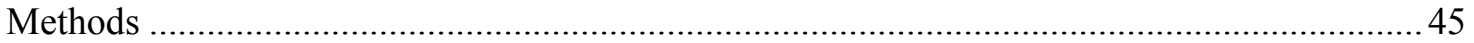

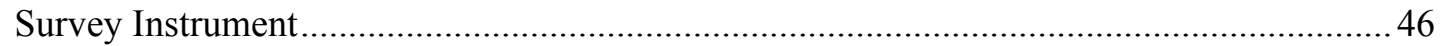




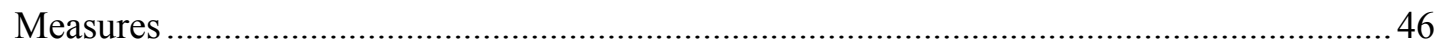

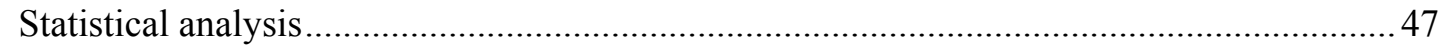

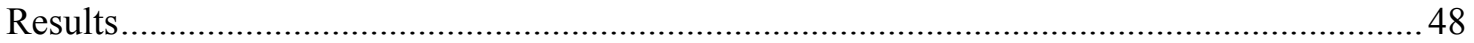

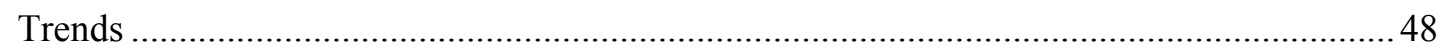

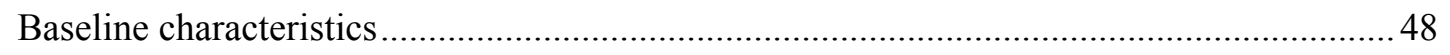

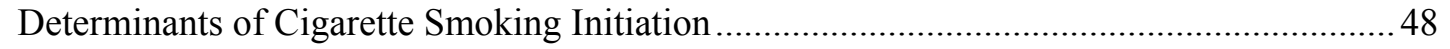

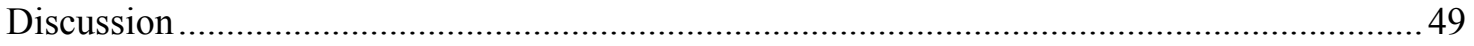

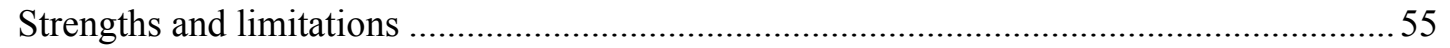

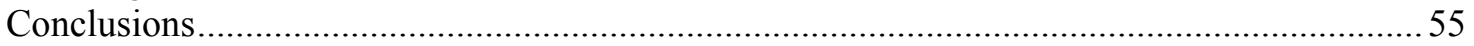

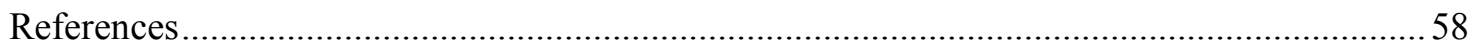

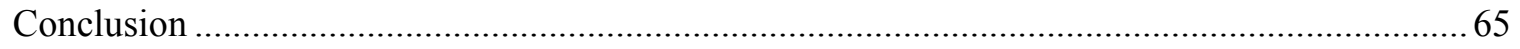

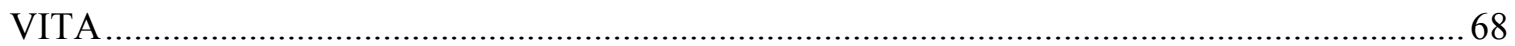




\section{LIST OF TABLES}

TABLE

PAGE

Table 1.1 Sociodemographic characteristics of school based sample of adolescents in Irbid,

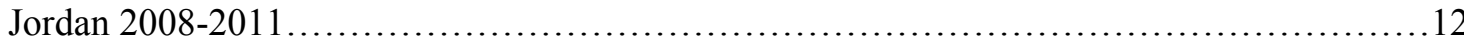

Table 1.2 Prevalence of smoking at each time point by gender and smoking method in a school based sample of adolescents in Irbid, Jordan 2008-2011....

Table 2.1 Survey questions with corresponding Attitude-Self efficacy-Social influence theoretical model domains and baseline characteristics of school based cohort $(\mathrm{N}=1,243)$ of Jordanian school children age $\approx 13$ at baseline, Irbid, Jordan, 2008-2011 (waterpipe initiators

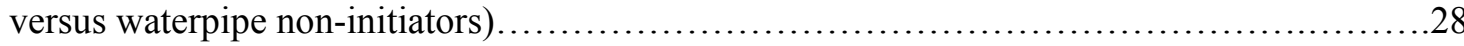

Table 2.2 Predictors of waterpipe smoking initiation, by gender, among school based cohort of school children aged 13 at baseline, Irbid, Jordan, 2008-2011: longitudinal analysis $(\mathrm{N}=1,243)$.

Table 3.1 Characteristics of school children $(\mathrm{N}=1,454)$ aged 13 at baseline Irbid, Jordan, 2008-2011. Cigarette initiators versus non-initiators

Table 3.2 Initiation of cigarette smoking among a school-based cohort $(\mathrm{N}=1,454)$ of Jordanian school children aged 13 at baseline, by gender, Irbid, 2008-2011 ...

Supplemental Table 3.3 Potential determinants of cigarette smoking initiation, by gender, among school based cohort of school children aged 13 at baseline, Irbid, Jordan, 2008-

2011: longitudinal analysis $(\mathrm{N}=$. 


\section{Introduction}

Smoking prevalence among adolescents in the Middle East remains high while rates of smoking have been declining among adolescents in other areas of the world. ${ }^{1,2}$ Decreasing rates of smoking initiation among adolescents have been achieved in the US and other industrialized countries as a result of policies and interventions that were implemented over time. ${ }^{3}$ These interventions and policies were evidence-based and typically founded on results from longitudinal studies. $^{4}$

Success in preventing smoking initiation among adolescents has not been observed in the Middle East, where effective smoking prevention programs are lacking and few tobacco control policies have been successfully implemented. This is due in part to the dearth of information regarding predictors of smoking initiation and progression among adolescents in this region. ${ }^{5}$ While the findings from developed countries can be useful in guiding intervention and policy planning, longitudinal studies of adolescent smoking from the same region are needed to establish causal relationships between predictive factors and smoking initiation/continuation in the Middle

East. The findings can then be used to develop appropriate, culturally sensitive smoking prevention programs and tobacco control policies. ${ }^{6-8}$

Most studies on youth smoking in the Middle East have collected data at a single time point $^{9-12}$ and have revealed a high prevalence of smoking ranging from 35\% among Jordanian university students to $52.8 \%$ among Lebanese university students. These studies have also consistently reported similar factors associated with smoking such as male gender, older age, peer influence, and higher socio-economic status. However, due to the cross-sectional nature of these studies, causal relationships between these predictors and smoking initiation cannot be determined. 
Additionally, few studies measure waterpipe (WP) smoking, which has proven to be of higher prevalence than cigarette smoking among youth in the Middle East, as reported by the Global Youth Tobacco Survey, ${ }^{13}$ and several other studies. ${ }^{14-16} \mathrm{WP}$ smoking is sometimes collapsed with cigarette smoking when reporting overall smoking prevalence ${ }^{11,12}$ and other studies do not report whether WP smoking was measured ${ }^{9}$ or focus solely on cigarette smoking. ${ }^{10}$ In the one report from a longitudinal study conducted in the region, which contains preliminary findings from the parent study of this dissertation research, WP smoking was found to be an important means of initiating and continuing smoking among Jordanian youth. This research also indicated that WP may influence cigarette-smoking behaviors, and vice-versa, in ways not yet fully understood. ${ }^{16}$ These findings point to the importance of concurrently measuring behaviors and beliefs related to smoking both cigarettes and WP, especially in the Middle East. By developing a thorough understanding of region- and country-specific predictors of smoking initiation, effective interventions tailored to the needs of specific subgroups of smokers can be developed.

\section{Parent study}

The data were collected from a school-based longitudinal study of adolescent smoking from 2008-2011 conducted in Irbid, Jordan. The source population was all students who were enrolled in the seventh grade (age 12-13 years) during the fall of 2008, in Irbid, Jordan (population $\sim 300,000$ ). There were 60 schools in Irbid, with a total of 5287 seventh graders. Stratified, cluster random sampling was used to obtain the study sample: a list of city school names and number of students was obtained from the Jordanian Department of Education. The schools were stratified by gender (male schools, female schools and mixed-gender schools) and by type (private or public) to ensure representative numbers of boys and girls from public and private schools in the study sample. A random sample of schools with probability proportional to size was selected from the roster of school names. Nineteen schools were selected ( 8 male, 9 
female, 2 mixed and 6 private). All seventh grade students in the selected schools were invited to enroll in the study and out of a total of 1877 students in these 19 schools, parental consents and student assents were provided by 1781 (95\%), all of whom were enrolled into the study.

\section{Theory}

The Attitude-Social influence-self-Efficacy (ASE) model was used to guide the choice of variables included on the survey instrument. This model has been successful in predicting smoking and other unhealthy behaviors. ${ }^{17}$ The ASE Model combines aspects of several wellknown and widely accepted theories (i.e. Bandura's Social Cognitive Theory, ${ }^{18}$ the Theory of Planned Behavior, ${ }^{19}$ the Health Belief Model, ${ }^{20}$ and the Transtheoretical Model). ${ }^{21}$ The ASE model states that behaviors are determined by a person's motivation or intention to carry out a particular type of behavior. Behavior is the result of a person's intentions plus abilities. Intentions can range from not contemplating behavioral change to contemplating changing the behavior very rapidly. A person's abilities, such as being able to plan specific actions to reach the goal behavior and intentions to implement these actions as well as actual skills, increase the chances of changing intentions into actions, while barriers can lower these chances. Potential risk factors from the modeled categories have been measured at each time point in the parent study. An additional advantage of this approach is that it allows for testing predictors of initiation vs. those

of later stages of transition to regular smoking. ${ }^{8,22}$ By accurately determining the extent to which each factor and/or groups of factors predict (or protect against) cigarette smoking initiation, progression, and/or cessation, these analyses will provide precise information useful in developing targeted smoking prevention and cessation interventions.

\section{Value of Dissertation Research}

This dissertation research was the first to analyze and report on the full dataset from the Irbid Longitudinal Smoking Study, which was the first longitudinal survey of tobacco use in adolescents conducted in the Middle East (Jordan), and the first longitudinal study that measured 
cigarette and WP smoking behaviors and related beliefs. The analyses provide critical information regarding the patterns of cigarette and WP use, as well as determinants of cigarette and WP smoking initiation in this population. Findings from this research can be used to help plan targeted prevention and cessation interventions, as well as to provide insight on the effectiveness of tobacco control policies. Ultimately, this knowledge could contribute to the development of a sustainable tobacco control infrastructure for the Middle East. 


\section{References}

1. El-Awa F, Warren C, Jones N. Changes in tobacco use for 13-15 year-olds between 1999 and 2007: Findings from the Eastern Mediterranean Region. Eastern Med Hlth J. 2010;16(3):266273.

2. Hipple B, Lando H, Klein J, Winickoff J. Global teens and tobacco: a review of the globalization of the tobacco epidemic. Curr Probl Pediatr Adolesc Health Care. 2011;41:216230 .

3. Giovino G. The tobacco epidemic in the United States. Am J Prev Med. 2007;33(6S):S316S326.

4. Chassin L, Presson C, Sherman S, Edwards D. The natural history of cigarette smoking: predicting young-adult smoking outcomes from adolescent smoking patterns. Health Psychology. 1990;9(6):701-716.

5. Maziak W, Eissenberg T, Klesges R, Keil U, Ward K. Adapting smoking cessation interventions for developing countries: a model for the Middle East. Int J Tuberc Lung Dis. 2003;8(4):403-412.

6. Robinson L, Murray D, Alfano C, Zbikowski S, Blitstein J, Klesges R. Ethnic differences in predictors of adolescent smoking onset and escalation: a longitudinal study from 7 th to 12 th grade. Nicotine Tob Res. 2006;8:297-307.

7. Gritz E, Prokhorov A, Hudmon K, Mullin Jones M, Rosenblum C, Chang C, et al. Predictors of susceptibility to smoking and ever smoking: a longitudinal study in a triethnic sample of adolescents. Nicotine Tob Res. 2003;5(4):493-506.

8. Hoving E, Mudde A, de Vries H. Smoking and the O pattern; predictors of transitions through the stages of change. Health Educ Res. 2006;21(3):305-314.

9. Abdalla A, Saeed A, Abdulrahman B, Al-Kaabba A, Raat H. Correlates of ever-smoking among adolescents in Tabuk, Saudi Arabia. Eastern Med Hlth J. 2009;15(4):983-992.

10. Farajat M. Beliefs of tenth grade Jordanian students regarding cigarette smoking. Saudi Med J. 2010;31(7).

11. Khader Y, Alsadi A. Smoking habits among university students in Jordan: prevalence and associated factors. Eastern Med Hlt J. 2008;14(4):897-904.

12. Tamim H, Musharrafieh U, Almawi W. Smoking among adolescents in a developing country. Australian New Zealand J Public Hlth. 2001;25(2):185-186.

13. World Health Organization. Retrieved from World Health Statistics. 2012; http://www.who.int/gho/publications/world_health_statistics/EN_WHS2012_Full.pdf 
14. Almerie M, Matar H, Salam M, Morad A, Abdulaal M, Koudsi A, et al. Cigarettes \& waterpipe smoking among medical students in Syria: a cross-sectional study. Int J Tuberc Lung Dis. 2008;12(9):1085-1091.

15. El-Roueiheb Z, Tamim H, Kanj M, Jabbour S, Alayan I, Musharrafieh U. Cigarette and waterpipe smoking among Lebanese adolescents, a cross-sectional study, 2003-2004. Nicotine Tob Res. 2008;10(2):309-314.

16. Mzayek F, Khader Y, Eissenberg T, Al Ali R, Ward K, Maziak W. Patterns of water-pipe and cigarette smoking initiation in school children: Irbid longitudinal smoking study. Nicotine Tob Res. 2011;14(4):448-454.

17. de Vries H, Mudde A. Predicting stage transitions for smoking cessation applying the attitude-social influence-efficacy model. Psychol Health. 1998;13:369-385.

18. Bandura A. Self-efficacy conception of anxiety. Anxiety Res. 1988;1:77-98.

19. Ajzen I. The theory of planned behavior. Organ Behav Hum Decis Processes. 1991;50:1-33.

20. Janz N, Becker M. The Health Belief Model: a decade later. Health Educ Q. 1984;11:1-47.

21. Prochaska J, DiClemente C. Stages and precesses of self-change of smoking: toward an integrative model of change. J Consult clin Psychol. 1983;51:390-395.

22. de Vries H, Mudde A, Leijs I, Charlton A, Vartiainen E, Buijs G, et al. The European Smoking Prevention Framework Approach (EFSA): an example of integral prevention. Health Educ Res. 2003;18(5):611-626. 


\section{Article 1}

McKelvey K, Wilcox M, Madhivanan P, Mzayek F, Khader, Maziak W. Time-trends of cigarette and waterpipe smoking among a cohort of school children in Irbid, Jordan 2008-2011. 2013. Eur J Public Health; 23(5):862-867.

\section{Abstract}

Background: Coordinated, high-impact interventions and community-level changes in smoking behavior norms effectively reduced prevalence of smoking among youth in many developed countries. Smoking trends among Jordanian adolescents are likely different than their western counterparts and must be understood in the context of their daily lives to tailor interventions specifically for adolescents in this setting.

Methods: Between 2008 and 2011, a school-based longitudinal study was conducted in Irbid, Jordan. All seventh-grade students in 19 randomly selected schools (out of 60) were surveyed annually for four years. Outcomes of interest were time trends in smoking behavior, age at initiation, and change in frequency of smoking.

Results: Among 1,781 participants, baseline prevalence of current smoking (cigarettes or waterpipe) for boys was $22.9 \%$ and $8.7 \%$ for girls. Prevalence of ever- and current any smoking, cigarette smoking, waterpipe smoking, and dual cigarette/waterpipe smoking was significantly higher in boys than girls each year $(\mathrm{p}<0.001)$. Smoking prevalence increased every year after year 2 for current smoking $(\mathrm{p}<0.05)$ across all methods (any, cigarette, waterpipe, and dual). At all time points for both boys and girls, prevalence of waterpipe smoking was higher than that of cigarette smoking $(\mathrm{p}<0.001)$.

Conclusion: This study shows intensive smoking patterns at early ages among Jordanian youth in Irbid, characterized by predominance of waterpipe smoking and steeper age-related increase in cigarette smoking. It also points to waterpipe being the favorite method for introducing youth to tobacco, as well as being a vehicle for tobacco dependence and cigarette smoking.

Keywords: adolescent, cohort, smoking, trends, waterpipe 


\section{Introduction}

In the developed world, huge successes in curbing the tobacco epidemic were achieved over the past 40 years due to a mixture of policies and interventions that led to the denormalization of smoking within the society. Much of the developing world, however, has not shared this success story, but witnessed an escalation in tobacco use instead. ${ }^{1,2}$ This was mostly due to the tobacco industry's effort to compensate for the loss of markets in countries with strong tobacco control regulations, and in many regions the emergence of new tobacco use methods most notably the waterpipe (WP) (a.k.a. hookah, shisha, narghile) ${ }^{3}$ In the Middle East, for example, where the WP has been known for centuries, recent years have witnessed a dramatic increase in its popularity, particularly among youth. In Middle Eastern countries where WP is popular, such as Lebanon, Jordan, and Syria, smoking prevalence among youth has reached staggering levels (e.g. 66\% among boys and 54\% among girls aged $13-15$ years in Lebanon). ${ }^{4}$

To curb the tobacco epidemic among youth, it is crucial to understand the patterns and determinants of tobacco use in this population. ${ }^{5}$ Yet, the local evidence-base needed to guide policy and interventions to curb smoking among youth in the Middle East is either lacking or arises from cross-sectional studies, which are limited in their usefulness for the identification of important determinants contributing to future smoking behaviors. An understanding of the dynamics of smoking behavior at the early stages of smoking acquisition among youth is necessary. Such an understanding can only be achieved through longitudinal studies with an adequate follow up period to allow monitoring of important trends in the smoking behavior of youth, and to study the influence of a wider variety of proximal and distal factors on youth smoking behavior. ${ }^{6,7}$ This study is the first longitudinal study of tobacco use behaviors among youth in the Middle East, with detailed information about cigarette and WP smoking, and with 4 data points, collected annually. The aim of this study is to describe the dynamics of tobacco use behavior among school children in Irbid (Jordan), in order to understand time-trends of tobacco 
use, cigarette and WP acquisition, and progression of tobacco use behavior among youth in Irbid. Such information will help guide interventions to curb tobacco use among youth in light of their early tobacco use trajectory, as well as according to age, gender, and tobacco use method. This may benefit tobacco control for youth not only in Irbid, but also in the rest of Jordan and in other countries in the Middle East that share many of the same tobacco use patterns. ${ }^{8}$

\section{Methods}

\section{Participants}

Detailed methodology of this study is published elsewhere. ${ }^{8,9}$ Briefly, from 2008 to 2011, we conducted a school-based longitudinal study among students who we followed from $7^{\text {th }}$ through $10^{\text {th }}$ grades in the city of Irbid, Jordan (population $\approx 330,000$ ). The cohort was surveyed annually. The 60 schools in the city were stratified by gender (boys, girls, mixed) and type of school attended (public and private). A cluster random sample of 19 schools ( 8 male, 9 female, 2 mixed and 6 private) was selected with probability proportional to size (PPS) to ensure representativeness of the sample. In 2008 , all $7^{\text {th }}$ grade students $(1,877)$ in the selected schools were invited to participate and 1,781 students (95\%) were enrolled in the study after obtaining parental consent and student assent.

Participants were followed prospectively by matching identification numbers each year. Follow-up rates each year were at least $89 \%$ (Y2=90\%; Y3=95\%; Y4=89\%) and over the study period, $83 \%$ of the participants completed all four surveys. At each time point, participants lost to follow-up were more likely to be male and baseline smokers (current, cigarette and/or WP). Differential participation within these groups may have weakened some results of this study. For example, the gap in current smoking prevalence between boys and girls may appear narrower since boys, who are more likely to be current smokers, were disproportionately lost to follow-up. 
This study was reviewed and approved by the IRBs of Jordan University for Science and Technology, University of Memphis, Syrian Society Against Cancer, and Florida International University.

\section{$\underline{\text { Survey Instrument }}$}

Development of the questionnaire was guided by international guidelines ${ }^{10}$ and other instruments that have been used and validated in Arabic. ${ }^{10,11}$ The questionnaire was composed of 6 sections pertaining to sociodemographics; tobacco use behavior (cigarette and WP); tobacco advertisement and warning labels; family and school environment; peer influences; and students' attitudes and beliefs regarding quitting smoking. Prior to the study, the questionnaire and study protocol were piloted among 86 boys and 67 girls from 4 schools in Irbid and modifications were introduced accordingly.

\section{Definitions}

A student was defined as an "ever smoker" if he/she reported ever experimenting with smoking. A student was defined as a "current smoker" if he/she reported smoking at least once within the past 30 days. "Age at initiation” was the reported age at which a student experimented with cigarette (or WP) for the first time. "Smoking frequency" among current smokers was dichotomized as "daily" vs. "less than daily" for cigarette use and "weekly" vs. "less than weekly" for WP use. Parental education was dichotomized into "less than high school" (ranging from illiterate to high school graduate) and "more than high school" education (at least some college).

Data analysis

Statistical analyses were performed using SPSS v21 (SPSS Inc., Chicago, IL) and Epi Info 7.0.9.34 (CDC, Atlanta, Georgia). All analyses were restricted to baseline participants $(\mathrm{n}=1,781)$. 
The data were described using frequency and percent of total for categorical variables, and mean and standard deviation (SD) for continuous variables. The prevalence at each time point was stratified by gender (boys/girls), smoking method (cigarette/WP) and smoking status (ever/current). Students who reported ever-smoking (cigarettes or WP) were counted as ever smokers at all subsequent time points. Chi-square test (or Fisher-exact test when appropriate) was used to compare prevalence by gender and smoking method. The chi-square test for trend (extended Mantel-Haenszel) was used to test linear trends in prevalence of smoking and smoking frequency among current smokers. We established a 2-tailed statistical significance level of $(\mathrm{p}<0.05)$. To account for the complex sampling design, all analyses were weighted by the school weight using 'Weight Cases' in SPSS v21. School weights were calculated by multiplying number of schools selected from each stratum with the probability of selecting a particular school and taking the inverse of the result.

\section{Results}

\section{Description of sample}

Of the 1,781 participants enrolled at baseline, a minimum of $89 \%$ were measured at each time point, with $1,482(83 \%)$ being measured at all time points. The mean age of the sample was $12.73( \pm 0.61)$ years at baseline. The sample was approximately half boys at each time point. At baseline, roughly half the participants' parents (55.1\% of fathers and $49.1 \%$ of mothers) had at least some college education. (Table 1) 
Table 1.1 Sociodemographic characteristics of school based sample of adolescents in Irbid, Jordan 2008-2011

\begin{tabular}{|c|c|c|c|c|}
\hline & $\begin{array}{c}\mathrm{N}=1781 \\
\text { Year } 1 \\
\text { n }(\%)^{*}\end{array}$ & $\begin{array}{c}\mathrm{N}=1597 \\
\text { Year } 2 \\
\text { n }(\%)^{*}\end{array}$ & $\begin{array}{c}\mathrm{N}=1687 \\
\text { Year } 3 \\
\text { n }(\%)^{*}\end{array}$ & $\begin{array}{c}\mathrm{N}=1587 \\
\text { Year } 4 \\
\mathrm{n}(\%) *\end{array}$ \\
\hline Age $($ mean \pm SD $)$ & $12.73 \pm 0.61$ & $13.31 \pm 0.65$ & $14.72 \pm 0.60$ & $15.72 \pm 0.61$ \\
\hline Boys & $915(50.4)$ & 797 (47.4) & 857 (48.7) & $795(47.5)$ \\
\hline Girls & $866(49.6)$ & $800(52.6)$ & $830(51.3)$ & $792(52.5)$ \\
\hline \multicolumn{5}{|l|}{ Father's education } \\
\hline$\leq$ high school & $864(44.9)$ & $783(45.7)$ & $820(45.4)$ & $757(44.6)$ \\
\hline$>$ high school & $916(55.1)$ & $813(54.3)$ & 865 (54.6) & $814(55.4)$ \\
\hline \multicolumn{5}{|l|}{ Mother's education } \\
\hline$\leq$ high school & $942(50.9)$ & $844(51.1)$ & $893(51.4)$ & $871(53.6)$ \\
\hline$>$ high school & $838(49.1)$ & 752 (48.9) & $794(48.6)$ & $704(46.4)$ \\
\hline \multicolumn{5}{|l|}{ Household size } \\
\hline$<8$ & $1276(71.8)$ & $1037(67.3)$ & $1160(69.5)$ & $1081(69.7)$ \\
\hline$\geq 8$ & $504(28.2)$ & $560(32.7)$ & $522(30.5)$ & $480(30.3)$ \\
\hline
\end{tabular}

*Weighted proportions are reported

Smoking behavior at year 1 (baseline)

Year 1 prevalence of ever- and current any smoking (cigarettes or WP) for boys was

$47.1 \%$ and $22.9 \%$, respectively, and $26.4 \%$ and $8.7 \%$ for girls. Prevalence of ever- and currentany smoking was $36.8 \%$ and $15.9 \%$ within the entire sample. For ever- and current cigarette smoking, the prevalence for boys was $26.9 \%$ and $8.0 \%$, respectively, and $10.6 \%$ and $2.3 \%$ for girls (18.8\% and 5.2\% overall). For ever- and current- WP smoking, the prevalence for boys was $39.2 \%$ and $20.6 \%$, respectively, and $24.1 \%$ and $7.7 \%$ for girls respectively $(31.7 \%$ and $14.2 \%$ overall). Ever- and current dual smoking of both cigarettes and WP was 19.0\% and 5.7\%, respectively, for boys and $8.3 \%$ and $1.3 \%$ for girls (13.7\% and $3.5 \%$ overall). Baseline smoking prevalence of ever- and current smoking (any, cigarette, WP, and dual smoking) was significantly higher among boys than girls ( $\mathrm{p}<0.001$ for all).

Time trends

Prevalence of ever- and current any smoking, cigarette smoking, WP smoking, and dual cigarette/WP smoking was significantly higher in boys than girls at all follow-ups $(\mathrm{p}<0.001)$. 
Smoking prevalence increased every year for ever smoking $(\mathrm{p}<0.001)$ and every year after year 2 for current smoking $(\mathrm{p}<0.05)$ across all methods (any, cigarette, WP, and dual). At all time points, the prevalence of WP smoking was significantly higher than that of cigarette smoking for both boys and girls $(\mathrm{p}<0.001)$. (Table 2$)$

Over the study period, the prevalence of ever smoking either cigarettes or WP increased overall by $80 \%$ and $67 \%$ among boys and $105 \%$ among girls. Prevalence of ever smoking cigarettes increased $130 \%$ among boys, $220 \%$ for girls, and $153 \%$ overall, while ever WP smoking increased by $79 \%$ among boys, $98 \%$ for girls, and $86 \%$ overall, and ever smoking dual cigarette/WP increased by $177 \%$ among boys, $230 \%$ for girls, and $189 \%$ overall.

Similarly, current any smoking (cigarettes or WP) increased $80 \%$ among boys, $136 \%$ for girls, and $91 \%$ overall. Current cigarette smoking increased $218 \%$ for boys, $226 \%$ for girls, and $208 \%$ overall, while current WP smoking increased by $72 \%$ for boys, $136 \%$ for girls, and $86 \%$ overall, and current smoking of both cigarettes and WP rose by $247 \%$ for boys, $300 \%$ for girls, $246 \%$ overall. All these trends were significant using chi-square test for trend ( $p<0.001$ for all).

\section{Age at initiation}

The majority of participants reported initiating cigarettes (54\% boys; $52 \%$ girls) and WP $(58 \%, 63 \%)$ between the ages of 11 and 14 while smoking initiation for both cigarette and WP steadily increased until ages 13-14. For cigarette smoking among girls, the prevalence dropped slightly from ages $11-12$ to age $\geq 15$, while for boys, the decrease between ages $13-14$ and $\geq 15$ was much greater. However, the decline in WP initiation between ages 11-12, 13-14, and $\geq 15$ was similar for boys and girls. It is notable that the largest drop in prevalence of initiation was evidenced at $\geq 15$ years old (see Figure 1 for details). 
Table 1.2 Prevalence of smoking at each time point by gender and smoking method in a school based sample of adolescents in Irbid, Jordan 2008-2011

\begin{tabular}{|c|c|c|c|c|c|}
\hline \multicolumn{6}{|c|}{$\underline{\text { BOYS }}$} \\
\hline \multirow[t]{2}{*}{ Smoking status } & $\begin{array}{r}\text { Year } 1 \\
\mathrm{~N}=915^{*}\end{array}$ & $\begin{array}{r}\text { Year } 2 \\
\mathrm{~N}=1014^{*}\end{array}$ & $\begin{array}{r}\text { Year } 3 \\
\mathrm{~N}=1068^{*}\end{array}$ & $\begin{array}{r}\text { Year } 4 \\
\mathrm{~N}=988^{*}\end{array}$ & \multirow[t]{2}{*}{$\begin{array}{r}X^{2} \text { Trend } \\
\text { p-value }\end{array}$} \\
\hline & $\mathrm{n}(\%)^{* *}$ & $\mathrm{n}(\%)^{* *}$ & $\mathrm{n}(\%)^{* *}$ & $\mathrm{n}(\%)^{* *}$ & \\
\hline Ever any & $421(47.1)$ & $529(61.8)$ & $637(69.4)$ & $688(78.6)$ & $<0.001$ \\
\hline Ever cigarettes & 245 (26.9) & $343(39.7)$ & $471(50.6)$ & $537(61.8)$ & $<0.001$ \\
\hline Ever waterpipe & $354(39.2)$ & $454(53.4)$ & $558(61.2)$ & $609(70.2)$ & $<0.001$ \\
\hline Ever both & $178(19.0)$ & $267(30.7)$ & $392(42)$ & $457(52.7)$ & $<0.001$ \\
\hline Current any & $213(22.9)$ & $212(24.1)$ & $294(32.9)$ & $339(41.1)$ & $<0.001$ \\
\hline Current cigarettes & $82(8.0)$ & $103(10.6)$ & $197(20.1)$ & $215(25.4)$ & $<0.001$ \\
\hline Current waterpipe & $185(20.6)$ & $177(20.9)$ & $209(23.8)$ & $284(35.5)$ & $<0.001$ \\
\hline Current both & $54(5.7)$ & $68(7.3)$ & $112(12.2)$ & $160(19.8)$ & $<0.001$ \\
\hline \multicolumn{6}{|c|}{$\underline{\text { GIRLS }}$} \\
\hline \multirow[t]{2}{*}{ Smoking status } & $\begin{array}{r}\text { Year } 1 \\
\mathrm{~N}=866^{*}\end{array}$ & $\begin{array}{r}\text { Year } 2 \\
\mathrm{~N}=976^{*}\end{array}$ & $\begin{array}{r}\text { Year } 3 \\
\mathrm{~N}=988^{*}\end{array}$ & $\begin{array}{r}\text { Year } 4 \\
\mathrm{~N}=937^{*}\end{array}$ & $\begin{array}{r}\text { Trend } \\
\text { p-value }\end{array}$ \\
\hline & $\mathrm{n}(\%)^{* *}$ & $\mathrm{n}(\%)^{* *}$ & $\mathrm{n}(\%)^{* *}$ & $\mathrm{n}(\%)^{* *}$ & \\
\hline Ever any & $204(26.4)$ & $293(37.8)$ & $391(47.3)$ & $443(54.0)$ & $<0.001$ \\
\hline Ever cigarettes & $82(10.6)$ & $153(19.3)$ & $225(26.6)$ & $285(33.9)$ & $<0.001$ \\
\hline Ever waterpipe & $184(24.1)$ & $264(34.4)$ & $354(43.2)$ & $386(47.8)$ & $<0.001$ \\
\hline Ever both & $62(8.3)$ & $124(15.9)$ & $188(22.4)$ & $226(27.4)$ & $<0.001$ \\
\hline Current any & $74(8.7)$ & $85(10.4)$ & $132(16.8)$ & $172(20.5)$ & $<0.001$ \\
\hline Current cigarettes & $20(2.3)$ & $30(3.5)$ & $53(5.7)$ & $67(7.5)$ & $<0.001$ \\
\hline Current waterpipe & $65(7.7)$ & $69(8.5)$ & $106(13.9)$ & $152(18.2)$ & $<0.001$ \\
\hline Current both & $11(1.3)$ & $14(1.6)$ & $27(3.2)$ & $47(5.2)$ & $<0.001$ \\
\hline
\end{tabular}

* Weighted proportions are reported.

** Participants who report ever smoking are counted as ever-smokers at all subsequent time points. 


\section{Smoking progression}

Among current smokers, we analyzed the time trend of daily and weekly use of cigarettes and WP, respectively. All trends were significant $(\mathrm{p}<0.001$ for all except girls daily cigarette smoking $\mathrm{p}<0.05$ ); however, the sole increasing trend in smoking frequency was for daily cigarette smoking in boys. Boys in particular reported more intensive smoking patterns compared to girls, with a larger proportion of boys reporting daily cigarette smoking at years 2 through 4 $(\mathrm{p}<0.001)$ and weekly WP smoking at years 3 and $4(\mathrm{p}<0.001)$. (See details in Figure 2$)$

\section{Discussion}

This is the first cohort study exploring the evolution of smoking behavior among youth (13-16 years) in a Middle Eastern country, and with detailed information about cigarette and WP smoking with 4 years of follow up. It shows that even at the early age of $13,16 \%$ of these youth in Irbid were already current smokers and more than one-third (37\%) of the sample had at least experimented with smoking by age 13. While WP smoking was more prevalent at every time point of this study and in both sexes, cigarette smoking showed a bigger increase during the 4 years of observation. Generally, girls showed the same predominance of WP smoking at every time point of the study, but generally at lower levels of smoking than boys for both cigarettes and WP. The time dynamics of smoking acquisition among girls seems in general about 2 years delayed compared to that of boys. Most youth smokers in this population initiated smoking before the age of 15, with the age group 11-12 showing the most intense smoking initiation for both boys and girls. Cigarette initiation among girls moreover, showed a delayed pattern compared to WP. Such information provides valuable insights about early tobacco use trajectories among youth in Irbid according to age, gender, and tobacco use method. These insights can guide interventions to curb tobacco use among youth in Irbid and perhaps Jordan overall, as well as other countries in the Middle East that share many of the same tobacco use patterns. ${ }^{18}$ 
Figure 1.1: Age of smoking initiation by smoking method and by gender among a school based sample of adolescents in Irbid, Jordan 2008-2011
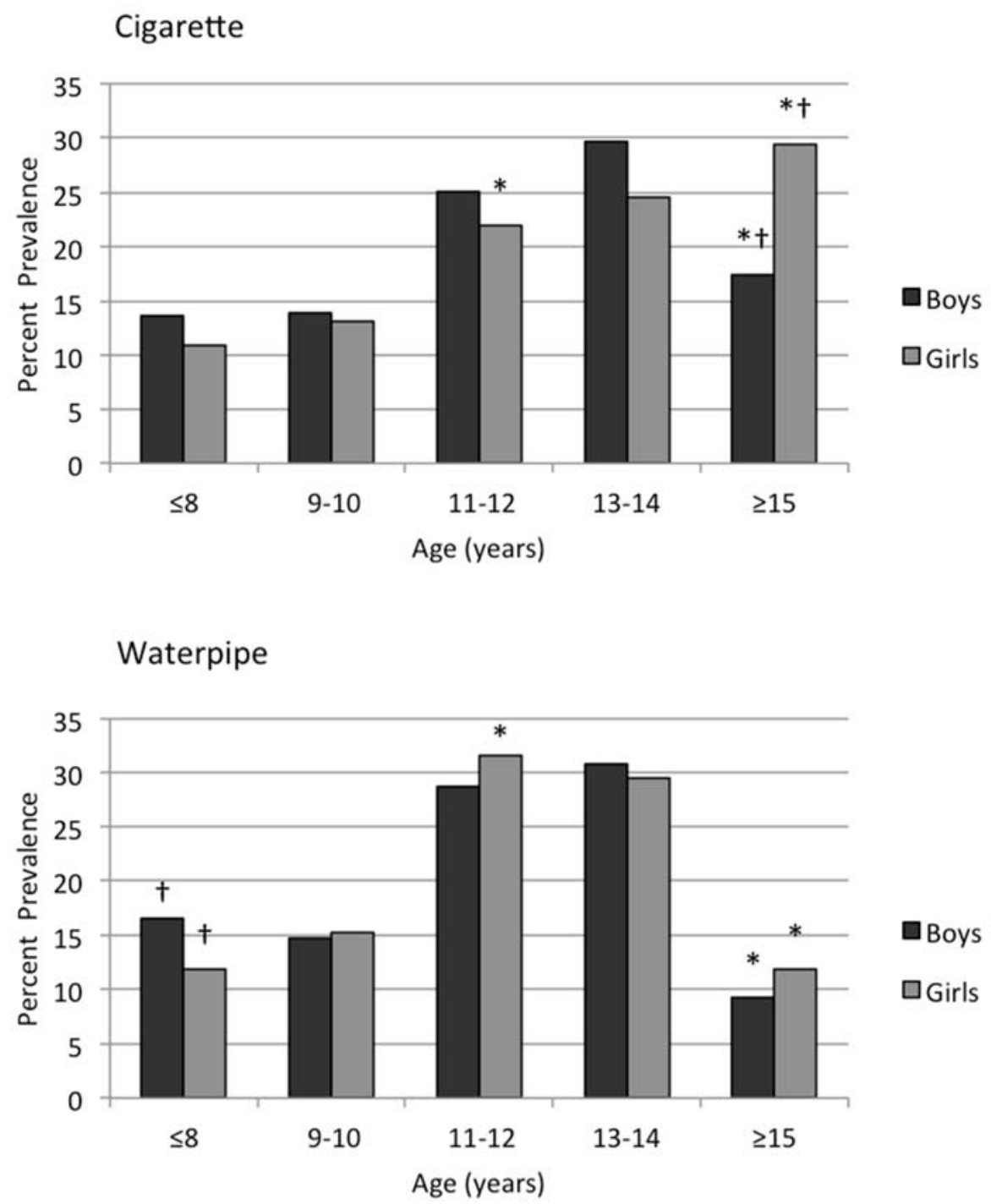

* Significant difference in smoking method within gender $(\mathrm{p}<0.05)$.

$\dagger$ Significant difference by gender within smoking method $(\mathrm{p}<0.05)$. 
Figure 1.2: Frequency of daily smoking of cigarettes and weekly smoking of waterpipe by gender among current smokers in a school based sample of adolescents in Irbid, Jordan 2008-2011

\section{Cigarette}
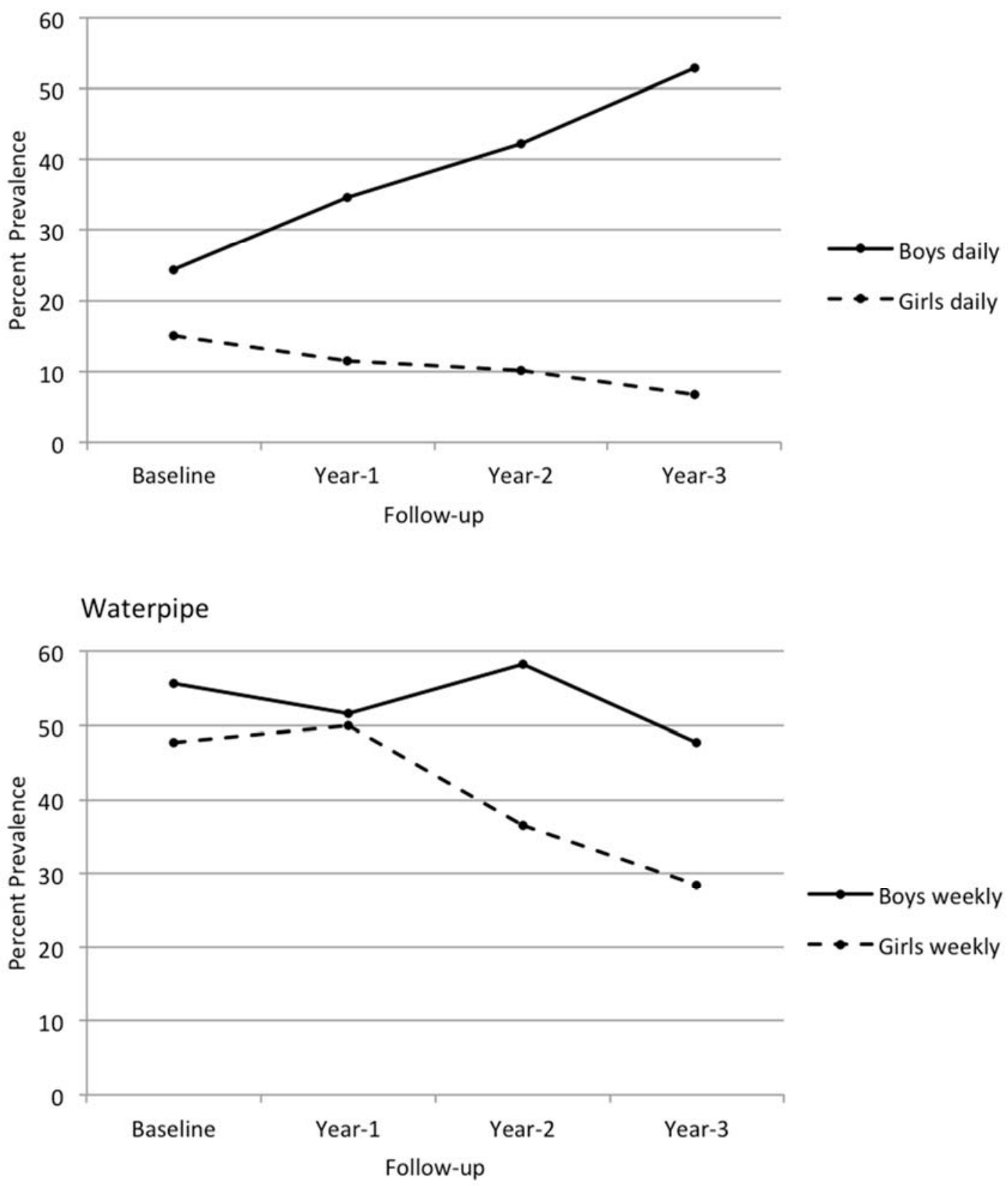

*Significant linear trend $(\mathrm{p}<.05)$ 
The predominance of WP smoking at early stages and the faster rise of cigarette smoking suggest that more youth are having their first experience with tobacco through the WP. Our results show generally that WP initiation is occurring at earlier stages compared to cigarettes. Whether this reflects more interest in experimenting with the exotic WP, ${ }^{12}$ societal tolerance for the culturally acceptable WP (especially for girls), ${ }^{13,14}$ a belief in WP's reduced harm and addictiveness,${ }^{15}$ or earlier exposure to the WP by family and peers remains to be seen. ${ }^{16}$ Most likely, it is a combination of all these and other factors, but a more systematic study of the predictors of WP initiation is needed to understand this phenomenon.

WP early predominance and steeper cigarette time trends also suggest that the WP can potentiate cigarette smoking among youth. In fact, an earlier study from the same cohort with a shorter follow-up showed that WP smokers at baseline were twice as likely as never-smokers to be current cigarette smokers two years later. ${ }^{9}$ One suggested mechanism for this could be the recently illustrated dependence-inducing properties of WP smoking in youth and its limited accessibility compared to cigarettes. ${ }^{17}$ Accordingly, once WP smokers become hooked on nicotine in a way that requires frequent dosing, cigarettes become a more practical way to obtain the "fix" compared to the WP, which requires time and arrangement for smoking. ${ }^{18}$

The gender difference in tobacco use method and time dynamics also suggest some interesting patterns. Generally, smoking among women/girls is less tolerated by traditional societies in the Middle East compared to men's smoking. ${ }^{13,18}$ As this and other studies suggest however, this gender-based intolerance to girls' smoking is less pronounced for the traditional/indigenous WP compared to the "Western" cigarettes..$^{13,16,18,19}$ So while girls in this study smoked mostly less than boys, the gender-based predominance of WP smoking (over cigarettes) was more pronounced for girls compared to boys. For example, at each time point of the study, current WP smoking was more than double that of cigarettes among girls, but the difference between the two tobacco use methods was less pronounced for boys. This is also 
supported by the later cigarette initiation by girls compared to boys shown in this study. These observations perhaps illustrate that experimenting with WP is a more culturally acceptable act for girls in traditional Middle Eastern societies compared to smoking cigarettes. ${ }^{4}$

This unfavorable environment for smoking by girls is likely influencing not only initiation/preference of WP vs. cigarettes, but also their smoking progression. Interestingly, while the frequency of daily smoking increased for boys, reflecting perhaps progression to dependence, the observed trend for girls was one of diminishing daily smoking. A decline in frequent users was also seen for girls' WP smoking -evidenced by the decrease in weekly smokers - despite the general increase in WP smoking among them. So while more girls seem to be experimenting with smoking as they grow up, their use patterns do not intensify as seen in boys. Another related interesting pattern is that in contrast to age-related increase in frequent cigarette smokers (daily smokers) among boys, the same was not noticed for the frequency of (weekly) WP smoking (which decreased). This is likely related to the earlier point suggesting switching to the more accessible cigarettes among the more nicotine dependent WP smokers among boys, but the traditional barrier for girls is somehow prohibiting such switch.

\section{Limitations and strengths}

One of the main limitations of this study is that all measures assessed were self-reported, which could result in underreporting of smoking, especially among girls, because of the social undesirability of girls' smoking in this region of the world. However, self-reported smoking has been strongly correlated with biomarkers of smoking in cohort studies of adolescents. ${ }^{20}$ Moreover, our previous experience studying smoking habits of youth in the Middle East shows that adolescents will share openly their smoking experiences provided that confidentiality and anonymity are assured..$^{21}$

On the other hand, this is the first cohort study to investigate this top priority public health problem among youth in the region. This study analyzes time trends of smoking assessed 
cross-sectionally at each time point; i.e. not the development of smoking for each study participant across time. This is intentional, because we wanted to draw a general picture of group behavior change across time rather than the progression of the smoking habit among individuals. While both types of information are important, they reflect different aspects of the problem with different implications for tobacco control in this population.

The presented information provides unique insights on time-related patterns that are gender- and tobacco-use- method specific among youth in Irbid, Jordan. The length and completeness of follow-up, combined with the detailed information of both smoking methods relevant to this population and region (cigarettes, and WP) add to the strength of this study.

\section{Conclusions}

This study shows intensive smoking patterns at early ages among youth in Irbid, characterized by early predominance of WP smoking and a steeper increase in cigarette smoking. It points at the possibility of WP being the favorite method for introducing youth to tobacco, as well as being a vehicle for tobacco dependence and cigarette smoking. Such information necessitates more attention to WP at early ages for any tobacco control strategy among youth in Irbid. The reasons behind this early predominance of WP and factors influencing the gender and tobacco use method-specific time-trends noticed in this study provide very valuable research questions for further studies aimed at understanding tobacco use and addiction among youth in Irbid, Jordan, and the Middle East. Going forward, risk and protective factors for initiation of cigarette and WP and the potential interaction of these smoking behaviors, together with further investigation of WP as a gateway to cigarettes are all viable avenues of investigation and could provide clear direction for smoking prevention interventions. 


\section{References}

1. Brinn M, Carson K, Esterman A, et al. Mass media interventions for preventing smoking in young people. Cochrane Database Syst Rev. 2010(11).

2. World Health Organization. The global burden of disease: 2004 update.

2008;:http://www.who.int/healthinfo/global_burden_disease/2004_report_update/en.

3. Centers for Disease Control and Prevention. Global youth tobacco surveillance 2000--2007.

Surveillance Summaries. 2008;57(SS01):1-21.

4. Maziak W, Ward K, Afifi-Soweid R, et al. Tobacco smoking using a waterpipe: a re-emerging strain in a global epidemic. Tob Control. 2004;13:327-333.

5. World Health Organization. World Health Statistics. 2012.

http://www.who.int/gho/publications/world_health_statistics/EN_WHS2012_Full.pdf .

6. O'Loughlin J, Karp I, Koulis T, et al. Determinants of first puff and daily cigarette smoking in adolescents. Am J Epidemiol. 2009;170(5):585-597.

7. DiFranza J, Savageau J, Fletcher K, et al. Symptoms of tobacco dependence after brief intermittent use the development and assessment of nicotine dependence in youth. Arch Pediatr Adolesc Med. 2004;161(7):704-710.

8. Maziak W, Nakkash R, Bahelah R, Husseini A, Fanous N, Eissenberg T. Tobacco in the Arab world: old and new epidemics amidst policy paralysis. Health Policy Plan. 2013:1-11.

9. Mzayek F, Khader Y, Eissenberg T, et al. Design, baseline results of Irbid, longitudinal, school-based smoking study. Am J Health Behav. 2011;35(6):746-755.

10. Mzayek F, Khader Y, Eissenberg T, et al. Patterns of water-pipe and cigarette smoking initiation in school children: Irbid longitudinal smoking study. Nicotine Tob Res. 2012;14(4):44854.

11. World Health Organization. Guidelines for controlling and monitoring the tobacco epidemic, 1997; Geneva.

12. Maziak W, Ward K, Afifi-Soweid R, et al. Standardizing questionnaire items for the assemssment of waterpipe tobacco use in epidemiological studies. Public Health. 2005;119(5):400-404.

13. Rastam S, Ward KET, Maziak W. Estimating the beginning of the waterpipe epidemic in Syria. BMC Public Health. 2004;4(23).

14. Maziak W, Rastam S, Eissenberg T, et al. Gender and smoking status-based analysis of views regarding waterpipe and cigarette smoking in Aleppo, Syria. Prev Med. 2004;38(4):479-484.

15. El-Roueiheb Z, Tamim H, Kanj M, et al. Cigarette and waterpipe smoking among Lebanese adolescents, a cross-sectional study, 2003-2004. Nicotine Tob Res. 2008;10:309-314. 
16. Jawaid A, Zafar A, Rehman T, et al. Knowledge, attitudes and practice of university students regarding waterpipe smoking in Pakistan. Int J Tuberc Lung D. 2008;12(9):1077-1084.

17. Maziak W, Eissenberg T, Rastam S, et al. Beliefs and attitudes related to narghile (waterpipe) smoking among university students in Syria. Ann Epidemiol. 2004;14:646-654.

18. Maziak W.The waterpipe: a new way of hooking youth on tobacco Am J Addict. 2013:1-5.

19. Cobb C, Ward K, Maziak W, et al. Waterpipe tobacco smoking: An emerging health crisis in the United States. Am J Health Behav. 2010;34(3):275-285.

20. Maziak W, Fouad F, Asfar T, et al. Prevalence and characteristics of narghile smoking among university students in Syria. Int J Tuberc Lung Dis. 2004;8(7).

21. Warren C, Jones N, Eriksen M, et al. Patterns of global tobacco use in young people and implications for future chronic disease burden in adults. The Lancet. 2006;367(9512):749-753. 


\title{
Manuscript 2
}

Determinants of waterpipe initiation in school children: A 4-year longitudinal analysis

\begin{abstract}
Objective: Guided by the Attitude-Social influence-self Efficacy (ASE) theory, this study identified predictors of waterpipe (WP) smoking initiation in a WP naïve cohort of Jordanian school children.
\end{abstract}

Methods: A school-based cohort of all $7^{\text {th }}$ grade students $(\mathrm{N}=1,781)$ in 19 of 60 schools in Irbid, Jordan, was followed from 2008 to 2011. Generalized linear mixed modeling was used to examine predictors of WP initiation among WP-naïve students $(\mathrm{N}=1,243)$.

Results: During the 3-year study, WP initiation was documented in 39\% of boys and $28 \%$ of girls. Prior cigarette smoking (boys: Odds Ratio 5.72; 95\% Confidence Interval 3.57- 9.17 \& girls: 6.62; 3.81-11.52) and low WP refusal self-efficacy (boys: 9.01; 5.19-15.66 \& girls: 11.75; $7.14,19.34)$ were strongly predictive of initiating WP. Boys were also more likely to initiate WP smoking if they had siblings $(2.44 ; 1.35-4.41)$ or teachers $(1.84 ; 1.09-3.09)$ who smoked and girls if they had a friend $(2.73 ; 1.67,4.46)$ or parents $(1.92 ; 1.18,3.13)$ who smoked.

Conclusion: There is a sizeable incidence of WP initiation among students of both sexes. These findings will help in designing culturally responsive prevention interventions against WP smoking. Gender-specific factors, refusal skills, and cigarette smoking need to be important components of such initiatives.

Keywords: cohort, gender, initiation, Jordan, school children, waterpipe 


\section{Introduction}

The global spread of waterpipe (WP) smoking among adolescents is widely documented.

${ }^{1-16}$ While the evidence is still preliminary, it suggests that WP smoking is as addictive and detrimental to health as cigarette smoking. ${ }^{17-24}$ Prevalence of WP smoking is high among school children in other parts of the world and is increasing among adolescents in the US. ${ }^{2,6-8,14,25-34} \mathrm{~A}$ recent 2011 review by Akl et al. reported prevalence for current WP smoking among school students in Estonia and Lebanon to be $21 \%$ and 25\% respectively; with estimates ranging from $12 \%-15 \%$ for Arab-Americans. In the US, a recent national survey of WP use among adolescents revealed ever-WP smoking prevalence of $7.3 \%$ and of large survey involving more than 100,000 students in 152 colleges found the prevalence of WP smoking to be $8.4 \%$, second only to cigarettes at $16.8 \% .{ }^{35} \mathrm{WP}$ popularity is partly fueled by the widespread misperception that it is safer alternative to cigarettes. ${ }^{7,36-38}$ Evidence however, shows that WP smoking is likely to be associated with many of the health risks of cigarette smoking. ${ }^{4,13,24,29}$

Despite the adverse public health implications of this resurging smoking method, there are no effective prevention or intervention strategies to curb its spread. ${ }^{23,39}$ One of the reasons that such efforts are delayed lies in the lack of knowledge about early stages of WP adoption and important factors influencing initiation. Most of the work about WP initiation has been based on cross-sectional studies and/or lacked guidance of an appropriate theoretical model of behavioral change. Recently, two longitudinal studies assessing predictors of WP initiation were conducted among college students in the US. ${ }^{26,40}$ While both studies reported high rates of initiation; they also reported high prevalence of ever-WP smoking at baseline, which emphasizes the need to study WP initiation dynamics at an earlier age. This evidence is in line with studies worldwide that suggest much of WP initiation occurs at younger ages. ${ }^{6,8,15,16,25,27,30,33,34,41,42}$

To address this knowledge gap, we employed the Attitude-Social influence-self-Efficacy (ASE) model as a framework for variable selection and interpretation. ${ }^{43,44}$ The ASE model 
incorporates insights from other tested and validated social cognitive theories, and suggests that behavior is the result of intentions and abilities, whereby motivational factors, such as various attitudes, social influences and self-efficacy, determine intention, while abilities and environmental barriers (e.g., availability, restrictions) determine whether intentions will be realized. ${ }^{45,46}$ Guided by the ASE model, this longitudinal study examined predictors of WP initiation among WP naïve school children in Jordan.

\section{Methods}

Detailed description of the methodology from this study is published elsewhere. . $^{3,29,33}$ Briefly, from 2008 to 2011 , school-based cohort of $7^{\text {th }}$ graders (at baseline) were surveyed annually through $10^{\text {th }}$ grade in the city of Irbid, Jordan. The 60 schools in the city of Irbid (Jordan) were stratified by gender (boys, girls, mixed) and type of school attended (public and private). A cluster random sample of 19 schools ( 8 male, 9 female, 2 mixed and 6 private) was selected with probability proportional to size (PPS). All $7^{\text {th }}$ grade students (age $\approx 13$ at baseline) in the selected schools were invited to participate. All selected schools and $95 \%$ of the students approached $(\mathrm{N}=1,781)$ agreed to participate in the study.

This study was reviewed and approved by the institutional review boards of Jordan University for Science and Technology, University of Memphis, Syrian Society Against Cancer and Florida International University.

\section{Survey Instrument}

Development of the study questionnaire was guided by the international guidelines of the World Health Organization (WHO) ${ }^{47}$, other previously used and validated instruments in Arabic and it was subsequently pilot-tested. ${ }^{42,48}$ The questionnaire included four modules: sociodemographics; cigarette smoking; WP smoking; and media and tobacco control. 


\section{Measures}

Initiation of WP was the main outcome. Initiation was defined as the change from "never smoker" (of WP) at baseline to "ever smoker" or "current smoker" (of WP) at any subsequent follow-up survey(s). A student was considered an "ever smoker" if he/she reported ever experimenting with smoking and a "current smoker" if he/she reported having smoked in the last 30 days. Assessed theoretical domains and corresponding survey questions are shown in Table 1. Variables were selected by choosing questions on our questionnaire that corresponded to domains in the ASE model as described in previous studies. ${ }^{43,49-52}$ Density Index (DI) is the number of persons living in a dwelling divided by the number rooms in a home (minus kitchen and bathrooms), which is a proxy for economic status that was used and tested previously in the Middle East. ${ }^{11,53}$

\section{$\underline{\text { Statistical analysis }}$}

All statistical analyses were performed using SAS version 9.3 (SAS Institute Inc., Cary, NC, 2011). The cohort for this analysis was derived from WP-naïve participants at baseline $(\mathrm{N}=1,243)$. The cohort was stratified by gender prior to analysis. SAS proc GLIMMIX was used for the analyses, which accounted for clustering of schools and the repeated measures during the follow-up in students. Questions with more than two possible response categories were analyzed in two ways: once as they were originally obtained, and the second time as binary. The variables were dichotomized by combining responses such as "maybe" and "sometimes" with "yes." "I don't know" answers were excluded from the analysis. We also combined "mother" and "father" into "parents" and "brother" and "sister" into "siblings." The results were robust, whether we used multiple categories or binary categories; binary categories were used for clarity of reporting. 54

Baseline characteristics were compared between WP initiators and non-WP initiators using chi-square test for categorical variables and t-test for continuous variables. Bivariate correlations for all predictor variables revealed no multicollinearity problems. This was inspected 
further by checking for extraordinary estimated coefficients and standard errors, which would have suggested the existence of colinearity. A "full(er)" model as described by Flom and colleagues (2007), ${ }^{55}$ that included all potential predictor variables, was then fitted using SAS proc GLIMMIX to find adjusted effects of each variable on initiation.

Odds ratios (OR) and 95\% confidence intervals (CI) were reported. P-values of $<0.05$ were considered significant. Weighted proportions to adjust for complex sampling design were reported throughout.

Results

Characteristics of sample

Baseline characteristics of 1,243 WP initiating and non-WP initiating participants are shown in Table 1. The participants who initiated WP were less likely to have fathers with more than a high school education; to have attended a public school; and to have reported they would accept WP from a friend. 
Table 2.1 Survey questions with corresponding Attitude-Self efficacy-Social influence theoretical model domains and baseline characteristics of school based cohort $(\mathrm{N}=1,243)$ of Jordanian school children age $\approx 13$ at baseline, Irbid, Jordan, 2008-2011 (waterpipe initiators versus waterpipe noninitiators)

\begin{tabular}{|c|c|c|c|}
\hline $\begin{array}{l}\text { Theoretical } \\
\text { Domain }\end{array}$ & Survey Questions & $\begin{array}{c}\text { Initiators } \\
(n=458)\end{array}$ & $\begin{array}{c}\text { Non- } \\
\text { initiators } \\
(n=785)\end{array}$ \\
\hline & & n (\%)* & n (\%)* \\
\hline & What is your gender? (Male) & $256(53.0)$ & 305 (40.8) \\
\hline & Have you ever smoked a cigarette, even a puff or two? & 47 (10.4) & $40(6.0)$ \\
\hline & Do you attend public school? & $412(85.2)$ & $641(67.2)$ \\
\hline Predisposing/ & How old are you? Mean (SD) & $12.7(0.6)$ & $12.6(0.6)$ \\
\hline \multirow[t]{4}{*}{ Demographics } & Density Index, ${ }^{b}$ Mean (SD) & $1.6(0.9)$ & $1.7(1.1)$ \\
\hline & How many years of education father has ( $>$ High School) & $145(33.1)$ & $273(40.4)$ \\
\hline & How many years of education mother has (>High School) & $104(25.3)$ & $190(27.7)$ \\
\hline & How much is your daily allowance? $(\geq 0.50 \mathrm{JOD})^{\mathrm{c}}$ & $73(18.6)$ & $120(19.3)$ \\
\hline \multirow[t]{2}{*}{ Awareness } & Do you think smoking WP is harmful for your health? & $421(92.1)$ & $710(90.8)$ \\
\hline & $\begin{array}{l}\text { Have you seen pro smoking ads in the media in the past } \\
\text { month? }\end{array}$ & $215(47.0)$ & $343(43.6)$ \\
\hline \multirow[t]{3}{*}{ Information } & $\begin{array}{l}\text { Have you seen ads warning about dangers of smoking on } \\
\text { health in the media in the past month? }\end{array}$ & $361(79.8)$ & $633(82.3)$ \\
\hline & $\begin{array}{l}\text { Have you seen warnings on WP tobacco packaging in the past } \\
\text { month? }\end{array}$ & $196(42.4)$ & $302(35.6)$ \\
\hline & $\begin{array}{l}\text { Has a family member warned you about dangers of WP } \\
\text { smoking? }\end{array}$ & $298(66.8)$ & $510(65.8)$ \\
\hline \multicolumn{4}{|l|}{ Motivation } \\
\hline Social & Does your family know you smoke cigarettes ${ }^{\mathrm{a}}$ ? & $10(23.8)$ & $10(29.8)$ \\
\hline \multirow[t]{5}{*}{ Influence } & Do your parent(s) smoke waterpipe? & $116(28.6)$ & $164(20.3)$ \\
\hline & Do your sibling(s) smoke waterpipe? & $52(11.0)$ & $69(9.3)$ \\
\hline & Do you have close friends who smoke waterpipe? & $108(22.3)$ & $133(18.7)$ \\
\hline & Have you seen actors on TV smoking? & $396(87.8)$ & $679(88.0)$ \\
\hline & Do your teachers smoke in front of students? & $198(42.0)$ & $212(23.3)$ \\
\hline Self Efficacy & Would you accept WP from friends if offered? & $52(12.4)$ & $39(6.2)$ \\
\hline \multirow[t]{4}{*}{ Attitude } & Do you think students who smoke WP have more friends? & $114(23.5)$ & $197(25.4)$ \\
\hline & Do you think student who smoke WP are more attractive? & $141(46.2)$ & $203(41.4)$ \\
\hline & Do you think smoking WP affects body weight? (lose weight) & $222(49.0)$ & $397(51.1)$ \\
\hline & $\begin{array}{l}\text { Do you think it is easy to stop smoking WP after smoking for } \\
\text { year or two? }\end{array}$ & $151(35.1)$ & $244(32.7)$ \\
\hline Intention & Do you think that you may start to smoke WP next year? & $42(9.3)$ & $61(8.3)$ \\
\hline
\end{tabular}

$*$ Weighted proportions reported to account for complex sampling design. $\mathrm{p}<0.05$ indicated in bold. ${ }^{\mathrm{a}} \mathrm{n}=47$ for initiators and $\mathrm{n}=40$ for non-initiators for ever smokers of cigarette at baseline. ${ }^{b}$ Density Index was calculated by dividing the number of people living in each participant's home by the number of rooms (minus kitchen and 
bathroom) in the home. ${ }^{\mathrm{c}}$ In Jordanian Dinars (JOD) (1JOD=1.41USD)

Smoking initiation incidence

Over the study period of 4 years, $36.8 \%$ of participants initiated WP (39.2\% of boys and $28.3 \%$ of girls). The largest proportion of participants initiated WP smoking at age $\approx 14$, in the $8^{\text {th }}$ grade (Figure 1).

Figure 2.1: Number of students initiating waterpipe by gender and year of follow up (2008-2011), Irbid, Jordan

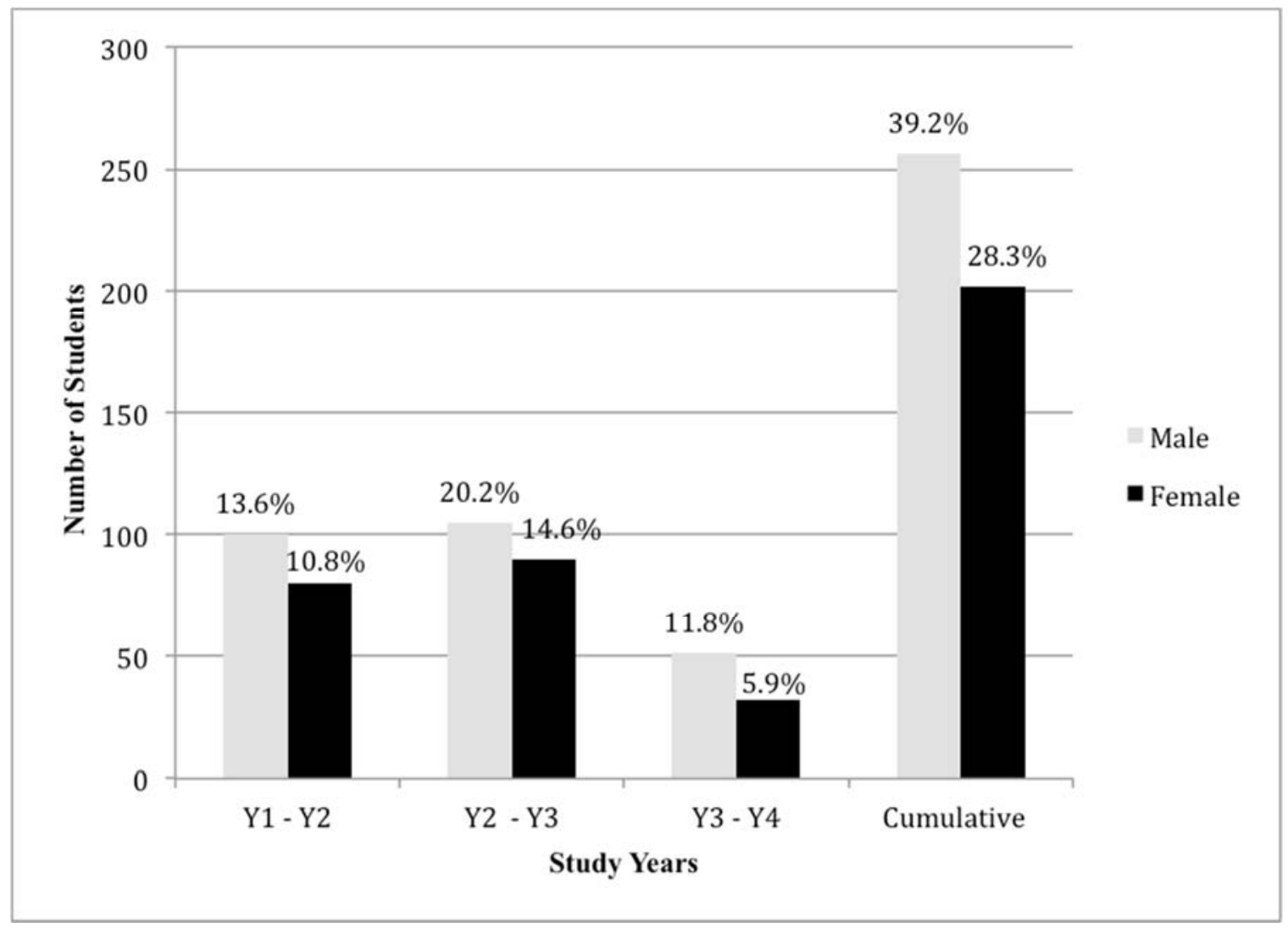

Weighted proportions are reported.

Association of ASE variables and WP smoking initiation by tenth grade

The results of the longitudinal analyses assessing the relationship between WP initiation by $10^{\text {th }}$ grade and potential predictor variables, stratified by gender, are summarized in Table 2 . 
Socio-economic status was not associated with WP smoking initiation in this sample. Previous cigarette smoking and low refusal self-efficacy were strongly associated with WP initiation. Teacher and sibling smoking were associated with initiation among boys while having friends who smoke was associated with initiation among girls. Awareness that WP smoking is harmful for health was protective against initiation (details in Table 2).

Initial analysis indicated significant effects of quit belief ("Is it easy to quit smoking WP after smoking for a year or two?”) on WP initiation among girls [OR $0.47 ;(0.24,0.94)]$, these results were not interpretable due to a suppression effect concerning quit belief. ${ }^{56}$ Quit belief was not correlated with the outcome (Spearman's $\quad 0.078 ; \mathrm{p}<0.150$ ). However, quit belief was significantly related to self-efficacy ("If a friend offers you a WP would you smoke it?") (Spearman's $=0.154 ; \mathrm{p}<0.01$ ), and further analyses showed suppression to take place when self-efficacy and/or intention and quit belief enter the model simultaneously. Self-efficacy was strongly related with intention ("Do you believe you will start smoking WP in the next year?") (Spearman's $=0.546 ; \mathrm{p}<0.01)$ and both self-efficacy $(0.451 ; \mathrm{p}<0.01)$ and intention $(437 ; \mathrm{p}<$ $0.01)$ were associated with the outcome. Therefore, we estimated models with each of these variables adjusted for all predictor variables, except the other two (e.g. self-efficacy was not adjusted for intention or quit belief). When quit belief was entered into the model without selfefficacy and intention, its association with the outcome was no longer significant. 
Table 2.2 Predictors of waterpipe smoking initiation, by gender, among school based cohort of school children aged 13 at baseline, Irbid, Jordan, 2008-2011: longitudinal analysis $(\mathrm{N}=1,243)$

\begin{tabular}{|c|c|c|c|c|c|}
\hline \multirow{2}{*}{$\begin{array}{l}\text { Theoretical } \\
\text { Domain }\end{array}$} & \multirow[b]{2}{*}{ Potential Predictor Variables ${ }^{\mathrm{a}}$} & \multicolumn{2}{|c|}{ Boys $(n=561)$} & \multicolumn{2}{|c|}{ Girls $(n=682)$} \\
\hline & & OR $(95 \% \mathrm{CI})$ & $\mathrm{AOR}^{*}(95 \% \mathrm{CI})$ & OR $(95 \% \mathrm{CI})$ & $\mathrm{AOR}^{*}(95 \% \mathrm{CI})$ \\
\hline \multirow{7}{*}{ 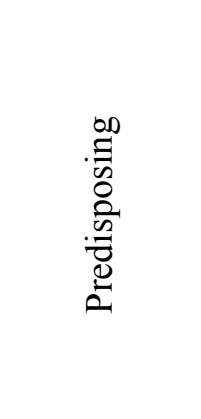 } & Smoke cigarettes & $7.17(5.03,10.20)$ & $7.41(4.05,12.92)$ & $9.93(6.55,15.05)$ & $8.48(4.34,16.56)$ \\
\hline & Density Index ${ }^{\mathrm{b}}$ (continuous) ${ }^{* *}$ & $0.89(0.74,1.07)$ & $1.07(0.80,1.43)$ & $0.91(0.74,1.11)$ & $1.02(0.72,1.45)$ \\
\hline & $\begin{array}{l}\text { Mother's education (> High } \\
\text { School) }\end{array}$ & $1.09(0.76,1.56)$ & $1.95(0.93,4.07)$ & $0.69(0.46,1.04)$ & $0.56(0.24,1.28)$ \\
\hline & $\begin{array}{l}\text { Father's education (> High } \\
\text { School) }\end{array}$ & $0.85(0.59,1.22)$ & $0.53(0.25,1.12)$ & $0.61(0.41,0.91)$ & $1.28(0.58,2.81)$ \\
\hline & Daily allowance $(\geq 0.50 \mathrm{JOD})^{\mathrm{c}}$ & $1.67(1.21,2.30)$ & $1.45(0.76,2.78)$ & $1.06(0.76,1.47)$ & $0.56(0.24,1.28)$ \\
\hline & Age in years (continuous) & $1.19(1.03,1.37)$ & $0.80(0.60,1.06)$ & $1.06(0.92,1.24)$ & $0.84(0.60,1.16)$ \\
\hline & Participation in sports & $3.43(1.94,6.07)$ & $4.28(1.60,11.43)$ & $1.29(0.82,2.02)$ & $0.68(0.31,1.49)$ \\
\hline \multirow{4}{*}{ Information } & $\begin{array}{l}\text { Propaganda encouraging } \\
\text { smoking }\end{array}$ & $1.28(0.92,1.78)$ & $1.11(0.62,2.00)$ & $1.20(0.87,1.66)$ & $1.50(0.84,2.69)$ \\
\hline & $\begin{array}{l}\text { Propaganda warning about } \\
\text { smoking }\end{array}$ & $0.89(0.62,1.28)$ & $0.88(0.46,1.67)$ & $0.72(0.48,1.06)$ & $2.15(0.96,4.82)$ \\
\hline & $\begin{array}{l}\text { Warning labels on WP tobacco } \\
\text { packages }\end{array}$ & $1.82(1.31,2.52)$ & $1.46(0.81,2.62)$ & $1.80(1.30,2.50)$ & $1.22(0.68,2.22)$ \\
\hline & $\begin{array}{l}\text { Warning of WP dangers from } \\
\text { family }\end{array}$ & $0.89(0.62,1.28)$ & $1.87(0.92,3.81)$ & $0.66(0.47,0.93)$ & $0.82(0.44,1.50)$ \\
\hline Awareness & Believe WP is bad for health & $0.38(0.24,0.59)$ & $0.39(0.17,0.88)$ & $0.34(0.20,0.59)$ & $0.36(0.13,0.98)$ \\
\hline \multirow{5}{*}{ 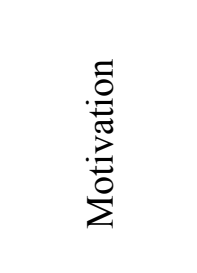 } & Parent(s) smoke WP & $2.10(1.44,3.06)$ & $1.06(0.56,2.03)$ & $3.53(2.53,4.94)$ & $1.79(0.97,3.33)$ \\
\hline & Sibling(s) smoke WP & $2.42(1.55,3.78)$ & $2.30(1.14,4.64)$ & $3.14(2.14,4.62)$ & $1.37(0.71,2.63)$ \\
\hline & Friends smoke WP & $3.37(2.35,4.84)$ & $0.68(0.36,1.29)$ & $5.82(4.09,8.29)$ & $2.96(1.59,5.54)$ \\
\hline & $\begin{array}{l}\text { Seen TV actors smoke in past } 30 \\
\text { days }\end{array}$ & $1.01(0.64,1.58)$ & $0.47(0.23,0.99)$ & $0.86(0.50,1.51)$ & $0.47(0.18,1.23)$ \\
\hline & Teachers smoke around students & $1.01(0.64,1.58)$ & $2.07(1.12,3.84)$ & $1.53(1.02,2.29)$ & $1.44(0.73,2.85)$ \\
\hline
\end{tabular}




\begin{tabular}{|c|c|c|c|c|c|}
\hline & Accept WP from friends ${ }^{\mathrm{d}}$ & $22.05(14.78,32.90)$ & $26.67(13.80,51.53)$ & $20.52(13.80,30.52)$ & $11.49(6.42,20.55)$ \\
\hline & $\begin{array}{l}\text { Believe have more friends if } \\
\text { smoke WP }\end{array}$ & $1.10(0.75,1.60)$ & $0.89(0.46,1.75)$ & $0.84(0.53,1.33)$ & $0.46(0.19,1.11)$ \\
\hline & $\begin{array}{l}\text { Believe more attractive if smoke } \\
\text { WP }\end{array}$ & $1.35(0.93,1.97)$ & $1.24(0.61,2.54)$ & $1.79(1.22,2.62)$ & $1.31(0.61,2.81)$ \\
\hline & WP weight belief $=$ lose weight & $0.93(0.67,1.30)$ & $1.05(0.59,1.85)$ & $0.80(0.58,1.10)$ & $0.88(0.49,1.58)$ \\
\hline & $\begin{array}{l}\text { Easy to quit after smoking WP } \\
\text { year or two }\end{array}$ & $2.00(1.44,2.78)$ & $1.35(0.86,2.14)$ & $1.31(0.92,1.85)$ & $0.76(0.45,1.27)$ \\
\hline Intention & $\begin{array}{l}\text { Intend to start smoking WP next } \\
\text { year }^{\mathrm{d}}\end{array}$ & $17.52(11.87,25.84)$ & $8.83(5.08,15.35)$ & $11.05(7.40,16.51)$ & $4.43(2.39,8.21)$ \\
\hline
\end{tabular}

OR $=$ Odds Ratio; $\mathrm{AOR}=$ Adjusted Odds Ratio; $\mathrm{CI}=$ Confidence Interval

*AOR for each variable is adjusted for all other variables in the model. Statistically significant adjusted odds ratios $(P$-value $<0.05)$ are in bold.

**For continuous variables, the OR approximates the risk change for every one-unit increase in the DI or one year increase in age.

${ }^{a}$ No is the referent category ${ }^{b}$ Density Index was calculated by dividing the number of people living in each participant's home by the number of rooms (minus kitchen and bathroom) in the home. ${ }^{\mathrm{c} I n}$ Jordanian Dinars (JOD) (1JOD=1.41USD) ${ }^{\mathrm{d}}$ Due to suppression effect, AOR for quit belief was not adjusted for intention or self-efficacy. Likewise, intention was not adjusted for quit belief or self-efficacy; nor was self-efficacy was adjusted for quit belief or intention. See text for detailed explanation. 


\section{Discussion}

Results of this study reveal annual incidence rates of WP initiation ranging from $6 \%$ $20 \%$ in school children followed from the $7^{\text {th }}$ to the $10^{\text {th }}$ grade. Over a third of youth initiated WP during the study period. More boys than girls initiated WP during this time and most participants initiated it around age 14. Those who took up WP smoking were more likely to attend a public (vs. private) school and have parents with less than a high school education. Outcomes lend some support for use of ASE-based variables in predicting WP smoking behaviors among youth in our study. Among predisposing variables, current cigarette smoking was associated with increased risk of WP initiation for boys and girls, and current involvement with sports was associated with increased risk for boys. Awareness about dangers of smoking was associated with decreased odds of initiation for boys and girls. Social influences to smoke were motivational risk factors for both boys and girls; however, effects differed by gender: for boys, social influences were sibling and teachers smoking and for girls it was friends smoking. Low refusal self-efficacy was another motivational factor that was strongly associated with initiation across both genders. Finally the odds of WP initiation were greater among those with an intention to smoke WP within the next year. These findings suggest that interventions should begin early, and target youth who attend public schools, and have not yet smoked. Effective interventions could include skill building to enhance children's refusal self-efficacy and resistance to social cues to smoke.

Although research on risk factors for WP initiation among adolescents is nonexistent, the temporal precedence of many predictors identified here fit with earlier longitudinal studies on adolescent cigarette smoking initiation. ${ }^{51,52,57-69}$ Research has frequently shown that predisposing factors such as use of other tobacco products is predictive of cigarette initiation. ${ }^{4,29,57}$ Some research has also shown that the peer influence common in team sports is associated with smoking behavior and that involvement in certain sports may be related to risk-taking, impulsivity, and consequently tobacco and other substance use. ${ }^{67,68}$ It is possible that youth who 
are attracted to the social nature of team sports may also be attracted to the social nature of WP, an activity usually shared in a group. ${ }^{16,28,70}$ Although the evidence is cross-sectional, an association between participation in organized sports and increased odds of WP smoking has been found among American collegiate athletes as well. ${ }^{5}$ The importance of the social environment - such as siblings', friends', and peer smoking behaviors, as well as role-model (e.g. teachers) smoking on cigarette smoking initiation has been underscored repeatedly in the literature. ${ }^{51,57,60-62,66}$ Alternately, certain personal factors we found to predict (low refusal selfefficacy) or protect against (health concerns) WP initiation have also been similarly associated with cigarette smoking initiation. ${ }^{51,52,57,60-62,66,69,71}$ Finally, in line with our findings, studies measuring smoking intention found this domain to be a strong predictor of cigarette initiation. ${ }^{63-65}$

Some cigarette research has provided outcomes counter to the findings in this WP initiation study. First, seeing actors smoke has been associated with cigarette initiation. ${ }^{59}$ It is likely our participants saw actors smoking cigarettes and not WP and that these modeled behaviors were interpreted by youth as very distinct. Finally, longitudinal research of cigarette initiation among youth that employed models similar to ASE identified strengths of some ASE domains to predict smoking that were not supported in our study. For example, motivational factors - such as positive attitudes and beliefs about smoking, like believing adolescents who smoke have more friends — have also been shown to influence cigarette-smoking uptake. ${ }^{58}$ Two cohort studies employing ASE (Denmark ${ }^{51}$ ) and social cognitive theory (Taiwan ${ }^{66}$ ) reported an association between adolescent cigarette smoking initiation and positive attitudes toward smoking. Our divergent findings may be due in part to our having stratified the sample by gender. Also, it is likely that attitudes regarding WP smoking in our sample are less pronounced, as the habit is ubiquitous in Jordan, eliciting weak; if any perceived attitudes compared to those which cigarette smoking does around the world. 
A potential weakness of this study was that all responses were self-reported and there may be a higher level of underreporting of smoking by girls due to the social undesirability of smoking among females in this area of the world. However, research among adolescents has shown strong agreement between self-reported smoking rates and those verified with biochemical measures. 72 Furthermore, our previous research among adolescents in the Middle East has also shown that youth are willing to share honestly about their smoking experience when confidentiality is assured. 28 Another potential limitation is that the ASE model may not sufficiently translate relevant cultural differences. One study examined the application of the ASE model to predict smoking among youth of different countries. ${ }^{73}$ The study found that the association between country of residence and intention to smoke was only partially mediated by ASE factors and that country also moderated cognitive factors associated with smoking intention. Despite these limitations, our study has several strengths that are important to note. This was the first longitudinal study of tobacco use in the Middle East and while the data were collected in one city, the sample was drawn from the entire population of $7^{\text {th }}$ graders in 2008 . Our study also collected smoking information simultaneously for both cigarette and WP. The high response and retention rates across four years also add to the strengths of this study.

\section{Conclusions}

Our study found that adolescents' efficacy to resist invitations to smoke is an important factor in actual WP smoking initiation. The influence of smoking by siblings, teachers, and friends were also predictive of WP initiation among youth in this study. Together these findings provide support for the development and implementation of "social influence" smoking prevention type interventions ${ }^{74,75}$ focused on enhancing the skills needed to resist social pressure to begin smoking WP. The influence of prior cigarette smoking on actual WP initiation, along with the mean initiation age (14 years) of this cohort, suggests that interventions need to begin early and target youth who have not yet smoked. Successful and early WP smoking prevention 
interventions that promote refusal efficacy will contribute to a sustainable foundation for regional tobacco control. 


\section{References}

1. Centers for Disease Control and Prevention (CDC). Tobacco product use among middle and high school students - United States, 2011 and 2012. MMWR Morb Mortal Wkly Rep. 2013;62(45):893.

2. Maziak W. The global epidemic of waterpipe smoking. Addict Behav. 2011;36(1-2):1-5.

3. Mzayek F, Khader Y, Eissenberg T, Ward K, Maziak W. Design, baseline results of Irbid longitudinal, school-based smoking study. Am J Health Behav. 2011;35(6):746-755.

4. Jensen PD, Cortes R, Engholm G, Kremers S, Gislum M. Waterpipe use predicts progression to regular cigarette smoking among Danish youth. Subst Use Misuse. 2010;45(7-8):1245-1261.

5. Primack BA, Fertman CI, Rice KR, Adachi-Mejia AM, Fine MJ. Waterpipe and cigarette smoking among college athletes in the United States. J Adolescent Health. 2010;46(1):45-51.

6. Primack BA, Walsh M, Bryce C, Eissenberg T. Water-pipe tobacco smoking among middle and high school students in Arizona. Pediatrics. 2009;123(2):e282-e288.

7. Eissenberg T, Ward K, Smith-Simone SY, Maziak W. Waterpipe tobacco smoking on a U.S. college campus: Prevalence and correlates. J Adolescent Health. 2008;42(5):526-529.

8. Parna K, Usin J, Ringmets I. Cigarette and waterpipe smoking among adolescents in Estonia: HBSC survey results, 1994-2006. BMC Public Health. 2008;8(1):392.

9. Maziak W, Ward K, Afifi Soweid RA, Eissenberg T. Tobacco smoking using a waterpipe: A re-emerging strain in a global epidemic. Tob Control. 2004;13(4):327-333.

10. Maziak W, Eissenberg T, Rastam S, et al. Beliefs and attitudes related to narghile (waterpipe) smoking among university students in Syria. Ann Epidemiol. 2004;14(9):646-654.

11. Maziak W, Rastam S, Eissenberg T, et al. Gender and smoking status-based analysis of views regarding waterpipe and cigarette smoking in Aleppo, Syria. Prev Med. 2004;38(4):479-484.

12. Maziak W, Eissenberg T, Klesges RC, Keil U, Ward K. Adapting smoking cessation interventions for developing countries: A model for the Middle East. Int J Tuberc Lung Dis. 2004;8(4):403-413.

13. Maziak W. The waterpipe: A new way of hooking youth on tobacco. Am J Addict. 2014;23(2):103-107.

14. Warren C, Lea V, Lee J, Jones NR, Asma S, McKenna M. Change in tobacco use among 13-15 year olds between 1999 and 2008: Findings from the global youth tobacco survey. Global Health Promotion. 2009;16(2S):38-90.

15. Primack BA, Mh J, Shensa A, Rosen D, Yonas MA, Fine MJ. Associations between race, ethnicity, religion, and waterpipe tobacco smoking. J Ethn Subst Abuse. 2014;13(1):58-71. 
16. Amrock SM, Gordon T, Zelikoff JT, Weitzman M. Hookah use among adolescents in the United States: Results of a national survey. Nicotine Tob Res. 2014;16(2):231-237.

17. Kassim S, Al-Bakri A, al'Absi M, Croucher R. Waterpipe tobacco dependence in U.K. male adult residents: A cross-sectional study. Nicotine Tob Res. 2014:16(3):316-325.

18. Maziak W, Rastam S, Shihadeh AL, et al. Nicotine exposure in daily waterpipe smokers and its relation to puff topography. Addict Behav. 2011;36(4):397-399.

19. Rastam S, Eissenberg T, Ibrahim I, Ward K, Khalil R, Maziak W. Comparative analysis of waterpipe and cigarette suppression of abstinence and craving symptoms. Addict Behav. 2011;36(5):555-559.

20. Eissenberg T, Shihadeh AL. Waterpipe tobacco and cigarette smoking: Direct comparison of toxicant exposure. Am J Prev Med. 2009;37(6):518-523.

21. Fromme H, Dietrich $\mathrm{S}$, Heitmann D, et al. Indoor air contamination during a waterpipe (narghile) smoking session. Food Chem Toxicol. 2009;47(7):1636-1641.

22. Al Rashidi M, Shihadeh AL, Saliba NA. Volatile aldehydes in the mainstream smoke of the narghile waterpipe. Food Chem Toxicol. 2008;46(11):3546-3549.

23. Maziak W, Eissenberg T, Ward K. Patterns of waterpipe use and dependence: Implications for intervention development. Pharmacol Biochem B. 2005;80(1):173-179.

24. Knishkowy B, Amitai Y. Water-pipe (narghile) smoking: An emerging health risk behavior. Pediatrics. 2005;116(1):e113-e119.

25. Akl E, Gunukula S, Aleem S, et al. The prevalence of waterpipe tobacco smoking among the general and specific populations: A systematic review. BMC Public Health. 2011;11(1):244.

26. Fielder RL, Carey KB, Carey MP. Prevalence, frequency, and initiation of hookah tobacco smoking among first-year female college students: A one-year longitudinal study. Addict Behav. 2012;37(2):221-224.

27. Martinasek MP, McDermott RJ, Martini L. Waterpipe (hookah) tobacco smoking among youth. Curr Prob Pediatr Adolesc Health Care. 2011;41(2):34-57.

28. Maziak W, Mzayek F. Characterization of the smoking habit among high school students in Syria. Eur J Epidemiol. 2000;16(12):1169-1176.

29. Mzayek F, Khader Y, Eissenberg T, Al Ali R, Ward K, Maziak W. Patterns of water-pipe and cigarette smoking initiation in school children: Irbid longitudinal smoking study. Nicotine Tob Res. 2012;14(4):448-454.

30. Prokhorov AV, Winickoff JP, Ahluwalia JS, et al. Youth tobacco use: A global perspective for child health care clinicians. Pediatrics. 2006;118(3):e890-e903. 
31. Rice VH, Weglicki LS, Templin TN, Jamil H, Hammad A. Intervention effects on tobacco use in Arab and non-Arab American adolescents. Addict Behav. 2010;35(1):46-48.

32. Weglicki LS, Templin TN, Rice VH, Jamil H, Hammad A. Comparison of cigarette and water-pipe smoking by Arab and non-Arab-American youth. Am J Prev Med. 2008;35(4):334339.

33. McKelvey KL, Wilcox ML, Madhivanan P, Mzayek F, Khader YS, Maziak W. Time trends of cigarette and waterpipe smoking among a cohort of school children in Irbid, Jordan, 2008-11. Eur J Public Health. 2013;23(5):862-867.

34. Barnett TE, Forrest JR, Porter L, Curbow BA. A multiyear assessment of hookah use prevalence among Florida high school students. Nicotine Tob Res. 2014;16(3)373-377.

35. Primack BA, Shensa A, Kim KH, et al. Waterpipe smoking among U.S. university students. Nicotine Tob Res. 2013;15(1):29-35.

36. Ak1 E, Jawad M, Lam WY, Co C, Obeid R, Irani J. Motives, beliefs and attitudes towards waterpipe tobacco smoking: A systematic review. Harm Reduct J. 2013;10(1):12.

37. Roskin J, Aveyard P. Canadian and english students' beliefs about waterpipe smoking: A qualitative study. BMC Public Health. 2009;9(10).

38. Maziak W, Ward K, Eissenberg T. Factors related to frequency of narghile (waterpipe) use: The first insights on tobacco dependence in narghile users. Drug Alcohol Depend. 2004;76(1):101-106.

39. Maziak W, Ward K, Eissenberg T. Interventions for waterpipe smoking cessation. Cochrane DB Syst Rev. 2007;4.

40. Sidani JE, Shensa A, Barnett TE, Cook RL, Primack BA. Knowledge, attitudes, and normative beliefs as predictors of hookah smoking initiation: A longitudinal study of university students. Nicotine Tob Res. 2013.

41. Nasim A, Khader Y, Blank MD, Cobb CO, Eissenberg T. Trends in alternative tobacco use among light, moderate, and heavy smokers in adolescence, 1999-2009. Addict Behav. 2012;37(7):866-870.

42. Warren C. The Global Youth Tobacco Survey Collaborative Group. Tobacco use among youth: A cross country comparison. Tob Control. 2002;11:52-70.

43. de Vries H, Dijkstra M, Kuhlman P. Self-efficacy: The third factor besides attitude and subjective norm as a predictor of behavioural intentions. Health Educ Res. 1988;3(3):273-282.

44. de Vries H, Mudde AN, Kremers S, et al. The European smoking prevention framework approach (ESFA): Short-term effects. Health Educ Res. 2003;18(6):649-663. 
45. Ajzen I. The theory of planned behavior. Organ Behav Hum Decis Process. 1991;50(2):179211.

46. Bandura A. Social cognitive theory: An agentic perspective. Annu Rev Psychol. 2001;52(1):126.

47. World Health Organization. Guidelines for controlling and monitoring the tobacco epidemic. Geneva: WHO. 1998;2000.

48. Maziak W, Ward K, Afifi Soweid RA, Eissenberg T. Standardizing questionnaire items for the assessment of waterpipe tobacco use in epidemiological studies. Public Health. 2005;119(5):400-404.

49. Kremers S, de Vries H, Mudde AN, Candel M. Motivational stages of adolescent smoking initiation: Predictive validity and predictors of transitions. Addict Behav. 2004;29(4):781-789.

50. de Vries H, Mudde AN. Predicting stage transitions for smoking cessation applying the attitude-social influence-efficacy model. Psychol Health. 1998;13(2):369-385.

51. Bidstrup PE, Frederiksen K, Siersma V, et al. Social-cognitive and school factors in initiation of smoking among adolescents: A prospective cohort study. Cancer Epidemiol Biomark Prev. 2009;18(2):384-392.

52. Ma H, Unger JB, Chou C, et al. Risk factors for adolescent smoking in urban and rural China: Findings from the china seven cities study. Addict Behav. 2008;33(8):1081-1085.

53. Maziak W, Asfar T. Physical abuse in low-income women in Aleppo, Syria. Health Care Women Int. 2003;24(4):313-326.

54. DeCoster J, Iselin AR, Gallucci M. A conceptual and empirical examination of justifications for dichotomization. Psychol Methods. 2009;14(4):349.

55. Flom, Peter L, and David L. Cassell. "Stopping stepwise: Why stepwise and similar selection methods are bad, and what you should use." NorthEast SAS Users Group Inc 20th Annual Conference: 11-14th November 2007; Baltimore. 2007.

56. Tu Y, Gunnell D, Gilthorpe M. Simpson's paradox, lord's paradox, and suppression effects are the same phenomenon - the reversal paradox. Emerging Themes in Epidemiology. 2008;5(1):2.

57. O'Loughlin JL, Karp I, Koulis T, Paradis G, DiFranza J. Determinants of first puff and daily cigarette smoking in adolescents. Am J Epidemiol. 2009;170(5):585-597.

58. Miller CH, Burgoon M, Grandpre JR, Alvaro EM. Identifying principal risk factors for the initiation of adolescent smoking behaviors: The significance of psychological reactance. Health Commun. 2006;19(3):241-252.

59. Morgenstern M, Sargent JD, Engels R, et al. Smoking in movies and adolescent smoking initiation: Longitudinal study in six European countries. Am J Prev Med. 2013;44(4):339-344. 
60. Hiemstra M, Otten R, de Leeuw RNH, van Schayck OCP, Engels R. The changing role of self-efficacy in adolescent smoking initiation. J Adolescent Health. 2011;48(6):597-603.

61. Hoving C, Reubsaet A, de Vries H. Predictors of smoking stage transitions for adolescent boys and girls. Prev Med. 2007;44(6):485-489.

62. Scal P, Ireland M, Borowsky I. Smoking among American adolescents: A risk and protective factor analysis. J Community Health. 2003;28(2):79-97.

63. Vitória PD, Salgueiro MF, Silva SA, de Vries H. Social influence, intention to smoke, and adolescent smoking behaviour longitudinal relations. Brit J Health Psychol. 2011;16(4):779-798.

64. Skara S, Sussman S, Dent CW. Predicting regular cigarette use among continuation high school students. Am J Health Behav. 2001;25(2):147-156.

65. Stanton WR, Barnett AG, Silva PA. Adolescents' intentions to smoke as a predictor of smoking. Prev Med. 2005;40(2):221-226.

66. Chang F, Lee C, Lai H, Chiang J, Lee P, Chen W. Social influences and self-efficacy as predictors of youth smoking initiation and cessation: A 3-year longitudinal study of vocational high school students in Taiwan. Addiction. 2006;101(11):1645-1655.

67. Fujimoto K, Unger JB, Valente TW. A network method of measuring affiliation-based peer influence: Assessing the influences of teammates' smoking on adolescent smoking. Child Dev. 2012;83(2):442-451.

68. Wood AP, Dawe S, Gullo MJ. The role of personality, family influences, and prosocial risktaking behavior on substance use in early adolescence. J Adolesc. 2013;36(5):871-881.

69. Tyas SL, Pederson LL. Psychosocial factors related to adolescent smoking: A critical review of the literature. Tob Control. 1998;7(4):409-420.

70. Blank MD, Brown KW, Goodman RJ, Eissenberg T. An observational study of group waterpipe use in a natural environment. Nicotine Tob Res. 2014;16(1):93-99.

71. Piko BF, Luszczynska A, Gibbons FX, Mert Teközel. A culture-based study of personal and social influences of adolescent smoking. Eur J Public Health. 2005;15(4):393-398.

72. Brener ND, Billy JO, Grady WR. Assessment of factors affecting the validity of self-reported health-risk behavior among adolescents: Evidence from the scientific literature. $J$ Adolescent Health. 2003;33(6):436-457.

73. Markham WA, Lopez ML, Aveyard P, et al. Mediated, moderated and direct effects of country of residence, age, and gender on the cognitive and social determinants of adolescent smoking in Spain and the UK: A cross-sectional study. BMC Public Health. 2009;9(1):173.

74. Best JA, Thomson SJ, Santi SM, Smith EA, Brown KS. Preventing cigarette smoking among school children. Annu Rev Public Health. 1988;9(1):161-201. 
75. de Vries H, Backbier E, Kok G, Dijkstra M. The impact of social influences in the context of attitude, self-efficacy, intention, and previous behavior as predictors of smoking onset. J Appl Soc Psychol. 1995;25(3):237-257. 


\section{Manuscript 3}

Determinants of cigarette smoking initiation in Jordanian school children: Longitudinal analysis

Abstract

Objective: To identify determinants of cigarette smoking initiation, by gender, among school children in Irbid, Jordan.

Methods: Between 2008 and 2011, data were collected using self-reported questionnaires annually over 4-years in a prospective cohort of 1,781 students recruited from all $7^{\text {th }}$ grade classes in 19 secondary schools, selected out of a total 60 , using probability-proportionate-to-size method. Independent predictors of smoking initiation were identified among the cigarette naïve participants $(\mathrm{N}=1,454)$ with mixed-effect multivariable logistic regression analysis using generalized mixed model.

Results: Participants were 12.6 years of age on average at baseline. $29.8 \%$ of the 1,454 students ( $37.2 \%$ of boys and $23.7 \%$ of girls) initiated cigarette smoking by $10^{\text {th }}$ grade. Of those who initiated ( $\mathrm{n}=498), 47.2 \%$ of boys and $37.2 \%$ of girls initiated smoking in the $8^{\text {th }}$ grade.

Determinants of cigarette smoking initiation included ever smoking a waterpipe, low cigarette refusal self-efficacy, intention to start smoking cigarettes, and having friends who smoked. For girls, familial smoking was also predictive of cigarette initiation.

Conclusion: This study shows that many Jordanian youth have an intention to initiate cigarette smoking and are susceptible to cigarette smoking modeled by peers and that girls are influenced as well by familial cigarette smoking. Prevention efforts should be tailored to address culturally relevant gender norms, help strengthen adolescents' self-efficacy to refuse cigarettes, and foster strong non-smoking social norms.

Keywords: adolescent, cigarette, gender, initiation, Jordan, longitudinal, waterpipe 


\section{Introduction}

Smoking has been characterized as the most important public health issue of our time. ${ }^{1}$

Most of the hazards of cigarette smoking are greatest for middle-aged smokers who began smoking as adolescents, but the short-term health consequences for adolescent smokers are serious as well. ${ }^{2}$ These include upper respiratory tract infections, reduced lung growth, reduction in maximum lung function, and poorer self-reported overall health. ${ }^{3-5}$ Still, in many countries, especially those in the developing world, the prevalence of smoking continues to increase among youth. ${ }^{6,7}$ While developed countries have the knowledge base and resources to try and reverse these trends, many developing countries like those found in the Eastern Mediterranean Region (EMR), still lack critical information about factors influencing early stages of the smoking habit. ${ }^{8}$

Both short-term and long-term health effects of smoking can be influenced by measures to prevent smoking initiation and progression during early stages of the smoking habit. ${ }^{9}$ Such work using a mixture of tobacco control policies and interventions is employed in many developed countries with considerable success. ${ }^{2,10,11}$ Generally, the establishment of the smoking habit among youth includes shared factors (e.g. addictive nature of nicotine), as well as more specific ones related to the cultural and contextual setting of the environment (e.g. local policy, societal attitude towards smoking). ${ }^{12-14}$ Therefore, understanding and highlighting some of the salient factors influencing cigarettes smoking initiation among youth is of paramount importance to start planning prevention and intervention strategies to reduce smoking amongst them. ${ }^{13-17}$ For instance, over the past decade, waterpipe (WP) smoking has become the most widespread tobacco use method among youth in the EMR. ${ }^{18}$ Even though WP smoking among adolescents has been shown to be associated with adolescent cigarette smoking in cross-sectional studies, longitudinal evaluation of its importance as a risk factor for youth cigarette uptake in the EMR and elsewhere is very limited. ${ }^{19-23}$ Additionally, the greater social tolerance of WP smoking for girls in the 
EMR, as compared to cigarette smoking, may heighten their risk for delayed cigarette initiation, which could pose a unique challenge to prevention efforts in the EMR. ${ }^{20,24-26}$

Integrative models applied to study adolescent smoking have positioned potential influences in terms of distance from the individual behavior - i.e. smoking — ranging from contextual (cultural norms and policies) to immediate social/normative (interpersonal interactions and relationships) to individual (preexisting behaviors, individuals' characteristics, beliefs and perceptions). ${ }^{9,27-29}$ Some of these integrative theories suggest that factors more "distant" from the individual may nonetheless be as powerful, if not more powerful, than individual factors in predicting youth smoking initiation. ${ }^{30,31}$ Contextual risk factors and those associated with social norms are important in the process of identifying potentially modifiable environmental factors for smoking initiation that are unique to different communities. ${ }^{8,9,13,16,32-41}$ Guided by these models, we followed a cohort of cigarette naïve school children in Irbid, Jordan for four years to examine gender-specific predictors of cigarette smoking initiation among Jordanian youth.

\section{Methods}

Detailed descriptions of the methodology for this study are published elsewhere. ${ }^{20,22,42}$ Briefly, data were drawn from a prospective cohort of 1,781 students (age $\approx 13$ at baseline) recruited in 2008 from all $7^{\text {th }}$ grade classes in a stratified cluster random sample with probability proportional to size of 19 ( 6 private, 8 all-male, 9 all-female, and 2 mixed) of the 60 schools in the city of Irbid, Jordan. All selected schools and $95 \%$ of the students agreed to participate in the study. Self-report questionnaires were administered at school by trained study personnel and collected once each school year through $10^{\text {th }}$ grade, for a total of 4 survey cycles.

This study was reviewed and approved by the institutional review boards of Jordan University for Science and Technology, University of Memphis, Syrian Society Against Cancer and Florida International University. 


\section{Survey Instrument}

Development of the questionnaire was guided by the international guidelines of the World Health Organization (WHO) ${ }^{43}$ and other previously used and validated instruments in Arabic. $^{44}$

\section{Measures}

The outcome measure, initiation of cigarette smoking, was defined as the change from "never smoker" (of cigarettes) at baseline to "ever smoker" or "current smoker" (of cigarettes) at any subsequent follow-up surveys. A student was considered a "never smoker" if he/she had never smoked a cigarette, not even a puff or two; an "ever smoker" if he/she reported ever experimenting with smoking; and a "current smoker" if he/she reported smoking within the last 30 days.

Sociodemographic covariates included age, gender, father's and mother's education, school type (public/private), daily pocket money, and density index (DI). The DI is calculated by dividing the number of people residing in the house by the number of its rooms (minus kitchen and bathrooms). Income was assessed indirectly using the DI, which is a proxy measure previously used and tested in the Middle East. ${ }^{45,46}$ Measures of social influences to smoke included mother, father, sibling, friend, teacher, and movie stars smoking. Attitudes favorable toward cigarette initiation were measured with questions regarding beliefs that smoking is associated with attractiveness and having more friends; perceived ease of quitting smoking; intention to start smoking. Attitudes considered unfavorable towards cigarette initiation were measured by asking whether smoking is bad for health. Self-efficacy to resist cigarettes was measured by asking whether the participant would smoke a cigarette if offered one by a friend. Finally, to assess the perceived relationships participants had with their parent/s, sibling/s, classmates, and teachers, we asked them to rate each relationship as "good," "normal," or "not good." 


\section{Statistical analysis}

The cohort for this analysis was derived from cigarette-naïve participants at baseline $(\mathrm{N}=1,454)$. Since differences in smoking behavior and societal perceptions and attitudes towards smoking were shown to be markedly different for males and females in the EMR, we stratified our sample by gender for the analysis of determinants of initiation. ${ }^{2,8,15,24,45,47-53}$

SAS proc GLIMMIX was used for the analysis to account for clustering of schools and the repeated measurements during the follow-up. To account for the complex sampling design, weights for each school were calculated by multiplying the number of schools selected from each stratum with the probability of selecting a particular school and taking the inverse of the result. A weight statement was used in the analysis where weight was calculated by dividing the original weight by the mean of the original weight (2.9540314). Proportions reported throughout were weighted in this manner.

Questions with more than two possible response categories were analyzed first in their original form, and then they were analyzed as binary. For example, multiple levels of education were collapsed from: Cannot read or write, $<6$ years, 6-12 years, University into $\leq$ high school vs. $>$ high school. We found the associations did not change whether we used multiple categories or binary categories; hence, we used binary categories in this paper for clarity of reporting. ${ }^{54}$

Baseline characteristics of those students who initiated cigarettes and those who did not were compared using chi-square tests for categorical variables and t-test for continuous variables. For all variables measured during the follow-up period, SAS proc GLIMMIX was used for the mixed logistic modeling, stratified by gender (boys \& girls). All predictors found to be significant at the p-value $<0.20$ level in the bivariate analysis were included in the multivariable analysis.

${ }^{55}$ To assess multicollinearity, correlations among independent variables were examined, as well as extraordinary estimated coefficients and standard errors were checked. Odds ratios (OR) and 95\% 
confidence intervals (CI) are reported. All statistical analyses were performed using SAS version 9.3 (SAS Institute Inc., SAS/STAT 9.3 User's Guide, Cary, NC: SAS Institute Inc., 2011).

Results

Trends

Of the entire sample ( $\mathrm{N}=1,781), 327$ participants (18.8\%) were ever-smokers of cigarettes at baseline. Of the remaining cohort of cigarette naïve students $(\mathrm{N}=1,454)$ the cumulative incidence of cigarette smoking initiation over 3 years was $37.2 \%$ for boys and $23.7 \%$ for girls. At all times, significantly more boys than girls initiated cigarette smoking. Between the $8^{\text {th }}$ and $9^{\text {th }}$ grades the greatest number of boys $(\mathrm{n}=128 ; 47.2 \%)$ and girls $(\mathrm{n}=72 ; 37.2 \%)$ initiated smoking cigarettes (Figure 1).

\section{Baseline characteristics}

Bivariate analysis showed initiators differed from non-initiators on several sociodemographic variables. Initiators were more likely to be males (OR 1.92; 95\% CI: 1.52 2.38), have parents with less than a high school education (fathers: $1.39 ; 1.10-1.75$; mothers: $1.30 ; 1.01-1.69)$, and attend public (vs. private) schools $(2.74 ; 2.05-3.66)$. Initiators and noninitiators did not differ by age, or economic status. Initiators had $1.92(1.48-2.49)$ times increased odds to report ever smoking WP, having at least one parent (1.66; 1.32-2.09), siblings (1.55; 1.15$2.08)$, friends $(1.57 ; 1.18-2.09)$, or teachers $(1.99 ; 1.56-2.52)$ who smoke. Initiators also had 2.12 (1.17-3.84) times increased odds to report low cigarette smoking refusal self-efficacy (Table 2).

\section{Determinants of Cigarette Smoking Initiation}

After controlling for sociodemographic covariates (gender, type of school [public/private] age, DI, father/mother education, daily pocket money), WP smoking, low refusal self-efficacy, intention to smoke cigarettes next year, and having friends who smoked cigarettes were independently predictive of cigarette smoking initiation for both boys and girls. Additionally, parental and sibling smoking were predictive of initiation of cigarette smoking (Table 3) among 
girls only. While not having good relationships with family and teachers, as well as having positive attitudes towards cigarette smoking, were risk factors for initiation in the bivariate analysis, these associations were not significant in the multivariable model.

\section{Discussion}

This is the first longitudinal study of smoking among adolescents in the EMR, and one of the very few to be conducted in the developing world. In this prospective cohort of 1,781 Jordanian school children, we found that nearly one-fifth were already smoking cigarettes at baseline (mean age 12.7 years). Of the cigarette naïve students, almost one-third began smoking cigarettes by $10^{\text {th }}$ grade (mean age 14.6 years); with boys just slightly more likely to initiate cigarette smoking compared to girls. For all participants, we found that a mixture of individual (e.g. ever smoked WP, poor refusal skills, intention to smoke) and social (e.g. friends smoking) factors were the most important determinants of smoking initiation. Additionally, solely for girls, familial (e.g. parents/siblings) smoking was a strong predictor of cigarette smoking initiation. These results provide valuable insights to understand smoking initiation among youth, as well as modifiable targets for efforts to reduce smoking among youth in Jordan and the EMR.

One of the unique features related to cigarette initiation in Jordan and the EMR, is its relation to WP smoking, which is even more popular than cigarettes. For example, ever WP smoking was a risk factor for cigarette initiation in our study, more so for girls than boys. Interestingly, WP smoking by girls does not face the same social taboo as cigarette smoking in the EMR. Our results therefore, can signify WP smoking as being a "gateway" to cigarettes, especially among girls. The WP delivers adequate amounts of nicotine to smokers, but it is considerably less accessible than cigarettes (e.g. requires a long time to setup and smoke and is much less portable). Those who become dependent on nicotine through the WP may resort to easily accessible cigarettes to satisfy their urge. ${ }^{56-61}$ Additionally, many cafés and restaurants in 
Figure 3.1.

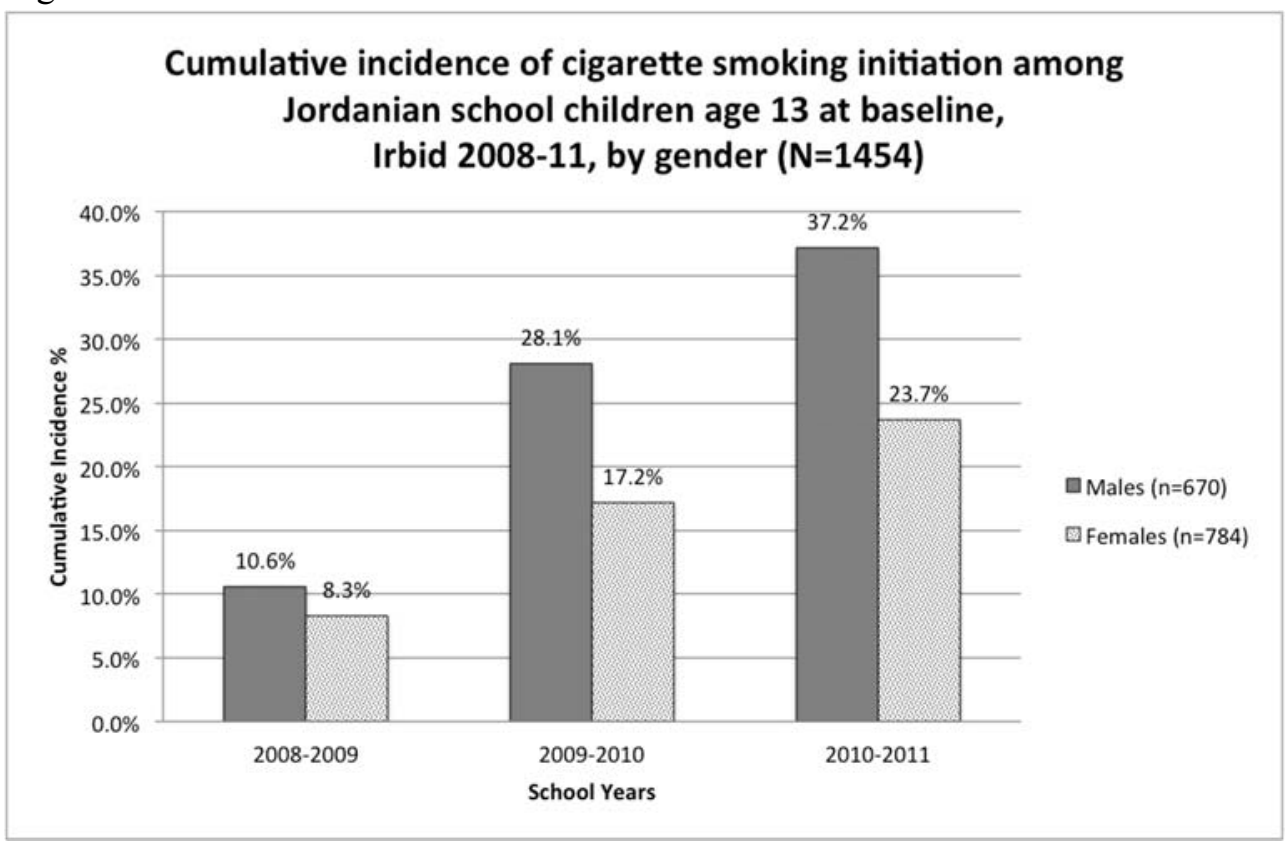

Weighted proportions are reported. 
Table 3.1 Characteristics of school children $(\mathrm{N}=1,454)$ aged 13 at baseline, Irbid, Jordan, 20082011; cigarette-smoking initiators versus non-initiators

\begin{tabular}{|c|c|c|c|c|c|}
\hline & Potential Determinants of Initiation & $\begin{array}{l}\text { Total } \\
\text { N(\%) }\end{array}$ & $\begin{array}{c}\text { Initiators } \\
(\mathrm{n}=495) \\
\mathrm{n}(\%)^{*}\end{array}$ & $\begin{array}{c}\text { Non- } \\
\text { initiators } \\
(\mathbf{n}=959) \\
\mathbf{n}(\%)^{*} \\
\end{array}$ & $\begin{array}{l}\text { p- } \\
\text { value }^{* *}\end{array}$ \\
\hline \multirow{7}{*}{ 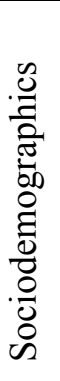 } & Males (vs. females) & $670(45.3)$ & $292(37.2)$ & $378(62.8)$ & 0.00 \\
\hline & Public school (vs. private) & $\begin{array}{r}1216 \\
(71.7)\end{array}$ & $445(84.4)$ & $771(66.4)$ & 0.00 \\
\hline & Age, mean $(\mathrm{SD})^{\mathrm{a}}$ & $12.7(0.6)$ & $12.8(0.5)$ & $12.7(0.6)$ & 0.22 \\
\hline & Density Index, mean (SD) & $1.7(1.0)$ & $1.7(1.0)$ & $1.6(1.0)$ & 0.77 \\
\hline & Father's education ( $>$ High School) & $520(39.9)$ & $160(34.5)$ & $360(42.2)$ & 0.01 \\
\hline & Mother's education (>High School) & $356(26.9)$ & $105(23.3)$ & $251(28.4)$ & 0.05 \\
\hline & Daily pocket money $(\geq 0.50 \mathrm{JOD})^{\mathrm{b}}$ & $261(21.1)$ & $83(19.9)$ & $178(21.5)$ & 0.48 \\
\hline \multirow{12}{*}{ 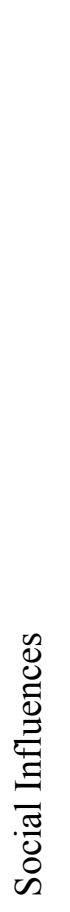 } & Ever-smoke waterpipe & $298(22.2)$ & $142(30.6)$ & $156(18.6)$ & 0.00 \\
\hline & Participate in sports & $\begin{array}{r}1038 \\
(75.0)\end{array}$ & $371(78.9)$ & $667(73.2)$ & 0.03 \\
\hline & $\begin{array}{l}\text { Seen ads promoting smoking last } 30 \\
\text { days }\end{array}$ & $670(45.4)$ & $249(51.5)$ & $421(42.9)$ & 0.01 \\
\hline & Seen ads against smoking last 30 days & $\begin{array}{r}1141 \\
(79.7)\end{array}$ & $383(77.8)$ & $758(80.5)$ & 0.23 \\
\hline & Seen cigarette package warnings & $\begin{array}{r}1275 \\
(87.4)\end{array}$ & $442(88.8)$ & $833(86.8)$ & 0.30 \\
\hline & $\begin{array}{l}\text { Family warned about dangers of } \\
\text { cigarettes }\end{array}$ & $\begin{array}{r}1121 \\
(76.5)\end{array}$ & $374(76.6)$ & $747(76.4)$ & 0.91 \\
\hline & Family knows smoke waterpipe & $166(57.2)$ & $77(55.0)$ & $89(58.8)$ & 0.50 \\
\hline & $\begin{array}{l}\text { Father and/or mother smoke } \\
\text { cigarettes }\end{array}$ & $733(49.7)$ & $281(58.6)$ & $452(46.0)$ & 0.00 \\
\hline & Sibling(s) smoke cigarettes & $237(16.1)$ & $103(20.4)$ & $134(14.2)$ & 0.01 \\
\hline & Friends smoke cigarettes & $247(17.1)$ & $114(21.9)$ & $133(15.1)$ & 0.01 \\
\hline & Seen actors smoking in media & $\begin{array}{r}1245 \\
(87.1)\end{array}$ & $418(85.2)$ & $827(87.9)$ & 0.17 \\
\hline & Teachers smoke around students & $492(30.0)$ & $209(40.6)$ & $283(25.6)$ & 0.00 \\
\hline \multirow{5}{*}{ 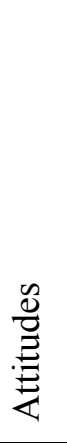 } & Believe cigarettes are bad for health & $\begin{array}{r}1351 \\
(93.6)\end{array}$ & $456(92.2)$ & $895(94.2)$ & 0.16 \\
\hline & $\begin{array}{l}\text { Believe students who smoke } \\
\text { cigarettes have more friends }\end{array}$ & $318(39.8)$ & $120(39.7)$ & $198(39.8)$ & 0.98 \\
\hline & $\begin{array}{l}\text { Believe students who smoke } \\
\text { cigarettes are more attractive }\end{array}$ & $503(48.3)$ & $191(54.7)$ & $312(45.3)$ & 0.01 \\
\hline & $\begin{array}{l}\text { Believe cigarettes affect weight (lose } \\
\text { weight) }\end{array}$ & $840(57.5)$ & $283(56.4)$ & $557(58.0)$ & 0.56 \\
\hline & $\begin{array}{l}\text { Believe it is easy to stop smoking } \\
\text { cigarettes after year or so }\end{array}$ & $425(29.8)$ & $149(29.3)$ & $276(30.1)$ & 0.77 \\
\hline
\end{tabular}




\begin{tabular}{|c|c|c|c|c|c|}
\hline \multirow{6}{*}{ 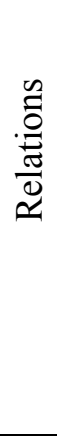 } & Relationship with parents (not good) & $39(2.8)$ & $14(2.8)$ & $25(2.8)$ & 0.95 \\
\hline & Relationship with siblings (not good) & $47(3.1)$ & $15(3.3)$ & $32(3.0)$ & 0.70 \\
\hline & $\begin{array}{l}\text { Relationship with classmates (not } \\
\text { good) }\end{array}$ & $56(3.9)$ & $17(3.7)$ & $39(4.0)$ & 0.08 \\
\hline & Relationship with teachers (not good) & $75(5.49)$ & $31(7.2)$ & $44(4.8)$ & 0.06 \\
\hline & Would accept cigarette from friends & $41(3.5)$ & $23(5.5)$ & $18(2.7)$ & 0.01 \\
\hline & $\begin{array}{l}\text { Intention to start smoking cigarettes } \\
\text { next year }\end{array}$ & $120(9.5)$ & $48(11.0)$ & $72(8.8)$ & 0.25 \\
\hline
\end{tabular}

Statistically significant p-values for chi-square for difference test are in bold.

* Standardized proportions are reported to account for complex sampling design.

** Chi-square test for equality of proportions p-value reported. 
Table 3.2 Determinants* of cigarette smoking initiation, by gender, among a cohort of school children aged 13 at baseline, Irbid, Jordan, 2008$2011(\mathrm{~N}=1,454)$

\begin{tabular}{|c|c|c|c|c|}
\hline \multirow[b]{2}{*}{ Determinants } & \multicolumn{2}{|c|}{ Boys $(n=670)$} & \multicolumn{2}{|c|}{ Girls $(n=784)$} \\
\hline & OR $(95 \% \mathrm{CI})$ & $\mathrm{aOR} * *(95 \% \mathrm{CI})$ & $\mathrm{OR}(95 \% \mathrm{CI})$ & $\mathrm{aOR} * *(95 \% \mathrm{CI})$ \\
\hline Smoke waterpipe & $6.12(4.30,8.70)$ & $3.43(2.06,5.69)$ & $9.13(6.28,13.27)$ & $5.38(3.43,8.42)$ \\
\hline Parents smoke cigarettes & $1.33(0.99,1.79)$ & $1.15(0.71,1.85)$ & $2.48(1.73,3.55)$ & $1.90(1.20,3.00)$ \\
\hline Sibling(s) smoke cigarettes & $1.55(1.11,2.18)$ & $0.91(0.53,1.55)$ & $2.48(1.75,3.51)$ & $1.75(1.11,2.75)$ \\
\hline Friends smoke cigarettes & $5.29(3.71,7.54)$ & $2.34(1.40,3.91)$ & $5.00(3.53,7.07)$ & $2.00(1.22,3.28)$ \\
\hline Accept cigarettes from friend & $23.32(15.91,34.17)$ & $10.67(6.14,18.56)$ & $12.74(8.48,19.14)$ & $4.95(2.70,9.08)$ \\
\hline Intend to start smoking cigarettes next year & $7.15(5.14,9.94)$ & $3.07(1.77,5.32)$ & $4.43(2.90,6.78)$ & $2.07(1.09,3.94)$ \\
\hline
\end{tabular}

OR = Odds Ratio (unadjusted); aOR = Adjusted Odds Ratio; CI = Confidence Interval

*Only determinants whose aOR did not include one, for either one or both genders are reported

$* *$ Odds ratios adjusted for all variables with $\mathrm{p}<0.20$ in bivariate analysis (see Supplemental Table). Statistically significant adjusted odds ratios $\mathrm{p}<0.05$ are in bold. 
the EMR cater to WP smokers, providing an environment where pro-smoking norms are pervasive, and perhaps conducive to tobacco use by adolescents. ${ }^{62-64}$ Intervention planning in Jordan and other places where WP is commonplace therefore, would need to address the WP and its harmful and addictive properties, as well as its potential to hook youth on nicotine and lead to cigarette smoking. ${ }^{65,66}$ Additionally, stronger anti-smoking policies that include WP smoking should be implemented and enforced to help avert cigarette uptake among adolescents in the EMR.

Poor refusal self-efficacy and intention to smoke have frequently been identified as strong predictors of adolescent cigarette initiation in developed countries. ${ }^{67-69}$ They have also been found to be indicative of "late-stage" smoking acquisition, where the adolescent has a clear intention to begin smoking. ${ }^{70}$ These factors were also strong predictors of cigarette smoking initiation in our population. This shows that patterns of initiation in different parts of the world and cultures share some aspects as well as have specific ones such as the WP in this case. Therefore, successful interventions focusing on strengthening refusal skills and self-efficacy in other societies are likely to be adaptable to the EMR. ${ }^{71,72}$

The influence of friends' smoking on both boys and girls in our sample is in line with theories emphasizing the power of peer modeling in the development of health behaviors among youth. ${ }^{32,40,45,52,73-79}$ One of the interesting findings in our study was that family smoking was strongly predictive of cigarette initiation for girls but not for boys. One interpretation could be that in the EMR, where there is greater societal disapproval and less tolerance for girls' cigarette smoking, smoking among family members may signify more tolerance towards the habit, and perhaps provide girls with more private access to experimentation with it. ${ }^{15,51}$ Boys on the other hand, would not be subjected to the same social taboo or "bad publicity," which seem to define a different contextual environment for initiation that is dominated by friends' smoking. ${ }^{45,52}$ As peer/family influence can be a risk for smoking initiation; they can be part of the solution as well. 
For example, the Truth Campaign of the American Legacy Foundation has utilized peers to promote healthy behaviors among adolescents, and helped reduce adolescent cigarette uptake. ${ }^{80}$

Tobacco control policies, such as banning advertisement and enforcing graphic warning labels have been shown to influence adolescents' cigarette uptake in developed countries. ${ }^{81-84}$ In Jordan, and perhaps other EMR countries, the situation seems to be different. For example, Jordan has graphic warning policy in place that requires covering $30 \%$ of the front and rear sides of the cigarette package. In our study, noticing such warnings was widespread among our students, yet it was not associated with smoking initiation. It is possible that in the absence of comprehensive tobacco control policy environment, single measures will not lead to changing the social norms, and thus will have lesser impact on smoking. ${ }^{31,84-86}$

\section{$\underline{\text { Strengths and limitations }}$}

A weakness of this study could be that all responses were self-reported and due to the social undesirability of cigarette smoking among females in Jordan, there may be a higher level of underreporting of smoking by girls. However, research has shown strong agreement between self-reported smoking rates among adolescents and those verified with biochemical measures. ${ }^{87}$ Additionally, our previous research among adolescents in the Middle East has found them willing to share honestly about their smoking experience when confidentiality is assured. ${ }^{88}$

\section{Conclusions}

Our results suggest that multiple levels of influences are involved in the onset of cigarette smoking among adolescents in Jordan, and that both individual level and social (family-friend) level factors are important in this regard. Some of these risk factors have also been identified among adolescents in developed countries and have been successfully addressed with multiple strategies including public health policy, clean indoor air laws, supportive school environment, and personal skills development. ${ }^{86}$ Components of these interventions therefore, can be adopted for use among youth in Jordan and perhaps the EMR, but they are unlikely to be effective unless 
they are dealt with within a comprehensive tobacco control package. Other factors, such as the effect of WP smoking on cigarette initiation, especially among girls, need to be addressed based on local evidence. Taken together, these findings could help form the basis for effective tobacco control interventions and policies in Jordan and provide a starting point for other similarly situated countries in their fight against youth tobacco use. 
Supplemental Table 3.3 Potential determinants of cigarette smoking initiation, by gender, among school based cohort of school children aged 13 at baseline, Irbid, Jordan, 2008-2011: longitudinal analysis $(\mathrm{N}=1,454)$

\begin{tabular}{|c|c|c|c|c|}
\hline \multirow[b]{2}{*}{ Predictor Variables } & \multicolumn{2}{|c|}{ Boys $(n=670)$} & \multicolumn{2}{|c|}{ Girls $(n=784)$} \\
\hline & OR $(95 \% \mathrm{CI})$ & $\mathrm{aOR} *(95 \% \mathrm{CI})$ & OR $(95 \% \mathrm{CI})$ & $\mathrm{aOR} *(95 \% \mathrm{CI})$ \\
\hline Age, mean (SD) & $1.23(1.08,1.40)$ & $1.24(0.97,1.58)$ & $1.16(1.00,1.35)$ & $1.03(0.82,1.29)$ \\
\hline Density Index (DI), mean (SD) ${ }^{\mathrm{a}}$ & $0.83(0.70,0.99)$ & $0.85(0.64,1.13)$ & $0.95(0.79,1.15)$ & $0.95(0.74,1.23)$ \\
\hline Public school (vs. private) & $4.82(2.73,8.52)$ & $2.89(1.43,5.84)$ & $2.10(0.87,5.06)$ & $2.87(1.30,6.34)$ \\
\hline Father's education ( $>$ High School) & $0.83(0.60,1.15)$ & $0.90(0.51,1.59)$ & $0.83(0.57,1.21)$ & $1.03(0.60,1.77)$ \\
\hline Mother's education (>High School) & $0.80(0.57,1.12)$ & $0.85(0.47,1.55)$ & $0.72(0.48,1.07)$ & $0.73(0.41,1.31)$ \\
\hline Daily pocket money $(\geq 0.50 \mathrm{JD})^{\mathrm{b}}$ & $1.57(1.16,2.11)$ & $0.79(0.45,1.38)$ & $1.48(1.07,2.04)$ & $1.01(0.61,1.68)$ \\
\hline Smoke waterpipe & $6.12(4.30,8.70)$ & $3.43(2.06,5.69)$ & $9.13(6.28,13.27)$ & $5.38(3.43,8.42)$ \\
\hline Participated in sports & $3.14(1.95,5.07)$ & $2.05(0.93,4.53)$ & $1.07(0.70,1.63)$ & \\
\hline Parents smoke cigarettes & $1.33(0.99,1.79)$ & $1.15(0.71,1.85)$ & $2.48(1.73,3.55)$ & $1.90(1.20,3.00)$ \\
\hline Sibling(s) smoke cigarettes & $1.55(1.11,2.18)$ & $0.91(0.53,1.55)$ & $2.48(1.75,3.51)$ & $1.75(1.11,2.75)$ \\
\hline Friends smoke cigarettes & $5.29(3.71,7.54)$ & $2.34(1.40,3.91)$ & $5.00(3.53,7.07)$ & $2.00(1.22,3.28)$ \\
\hline Would accept cigarettes from friend & $23.32(15.91,34.17)$ & $10.67(6.14,18.56)$ & $12.74(8.48,19.14)$ & $4.95(2.70,9.08)$ \\
\hline Teachers smoke around students & $3.45(2.44,4.89)$ & $1.60(0.95,2.70)$ & $1.84(1.26,2.69)$ & $1.21(0.74,1.99)$ \\
\hline Seen pro-smoking ads in last 30 days & $1.46(1.08,1.96)$ & $1.22(0.73,1.89)$ & $1.07(0.78,1.47)$ & \\
\hline Family warned about dangers of cigarette smoking & $0.65(0.45,0.95)$ & $0.88(0.47,1.63)$ & $0.66(0.45,0.96)$ & $1.32(0.73,2.39)$ \\
\hline Seen warning labels on cigarette pack in last 30 days & $1.07(0.71,1.61)$ & $\mathrm{c}$ & $1.54(0.86,2.77)$ & $0.96(0.47,1.97)$ \\
\hline Believe students who smoke cigarettes are more attractive & $1.32(0.95,1.83)$ & $0.63(0.35,1.11)$ & $1.41(0.99,2.00)$ & $0.88(0.55,1.42)$ \\
\hline Believe students who smoke have more friends & $1.44(1.05,1.98)$ & $1.15(0.68,1.96)$ & $1.12(0.75,1.67)$ & $\mathrm{c}$ \\
\hline Believe easy to stop smoking cigarettes after year or so & $1.60(1.19,2.15)$ & $1.49(0.93,2.39)$ & $1.14(0.80,1.63)$ & $\mathrm{c}$ \\
\hline Intend to start smoking cigarettes next year & $7.15(5.14,9.94)$ & $3.07(1.77,5.32)$ & $4.43(2.90,6.78)$ & $2.07(1.09,3.94)$ \\
\hline Relationship with parents (not good) & $1.70(0.89,3.27)$ & $1.13(0.36,3.57)$ & $1.64(0.72,3.76)$ & \\
\hline Relationship with siblings (not good) & $1.74(0.85,3.60)$ & $0.89(0.22,3.56)$ & $1.86(0.84,4.11)$ & $1.00(0.30,3.27)$ \\
\hline Relationship with teachers (not good) & $2.80(1.77,4.42)$ & $1.55(0.69,3.48)$ & $2.11(1.18,3.77)$ & $1.30(0.55,3.04)$ \\
\hline
\end{tabular}

$\mathrm{OR}=$ Odds Ratio (unadjusted); aOR = Adjusted Odds Ratio; $\mathrm{CI}=$ Confidence Interval;

*Odds ratios adjusted for all variables in the listed model. Variables with $\mathrm{p}>0.20$ in bivariate analysis were excluded from the final model. Statistically significant adjusted odds ratios $\mathrm{p}<0.05$ are in bold.

a Density Index is calculated by dividing the number of people reported living in each participant's home by the number of people rooms in the dwelling (minus kitchen and bathrooms). ${ }^{b}$ In Jordanian Dinars (JOD) ( $\left.1 \mathrm{JOD}=1.41 \mathrm{USD}\right)^{\mathrm{c}}$ Association at $\mathrm{p}<0.20$ in bivariate analysis for one gender and thereby included in final model for that gender, but not the other 


\section{References}

1. Williams CL, Hayman LL, Daniels SR, et al. Cardiovascular health in childhood: A statement for health professionals from the committee on atherosclerosis, hypertension, and obesity in the young (AHOY) of the council on cardiovascular disease in the young, American heart association. Circulation. 2002;106(1):143-160.

2. Thun M, Peto R, Boreham J, Lopez AD. Stages of the cigarette epidemic on entering its second century. Tob Control. 2012;21(2):96-101.

3. US Department of Health and Human Services. Preventing tobacco use among youth and young adults: A report of the surgeon general. Atlanta, GA: US Department of Health and Human Services, Centers for Disease Control and Prevention, National Center for Chronic Disease Prevention and Health Promotion, Office on Smoking and Health. 2012;3.

4. Holmen TL, Barrett-Connor E, Holmen J, Bjermer L. Health problems in teenage daily smokers versus nonsmokers, Norway, 1995-1997: The Nord-Trondelag health study. Am J Epidemiol. 2000;151(2):148-155.

5. Flouris AD, Faught BE, Klentrou P. Cardiovascular disease risk in adolescent smokers: Evidence of a 'smoker lifestyle'. J Child Health Care. 2008;12(3):221-231.

6. Mackay J, Eriksen M, Shafey O. The tobacco atlas, 2nd. Atlanta, GA: American Cancer Society. 2006.

7. Warren C. The Global Youth Tobacco Survey Collaborative Group. Tobacco use among youth: A cross country comparison. Tob Control. 2002;11:52-70.

8. Global Youth Tobacco Survey Collaborating Group. Differences in worldwide tobacco use by gender: Findings from the global youth tobacco survey. J Sch Health. 2003;73(6):207-215.

9. US Department of Health and Human Services. Preventing tobacco use among youth and young adults: A report of the surgeon general. Atlanta, GA: US Department of Health and Human Services, Centers for Disease Control and Prevention, National Center for Chronic Disease Prevention and Health Promotion, Office on Smoking and Health. 2012.

10. Lopez AD, Collishaw NE, Piha T. A descriptive model of the cigarette epidemic in developed countries. Tob Control. 1994;3(3):242.

11. Derzon JH, Lipsey MW. Predicting tobacco use to age 18: A synthesis of longitudinal research. Addiction. 1999;94(7):995-1006.

12. Fernander A, Resnicow K, Viswanath K, Pérez-Stable EJ. Cigarette smoking interventions among diverse populations. American Journal of Health Promotion. 2011;25(sp5):S1-S4. 
13. Kong G, Singh N, Krishnan-Sarin S. A review of culturally targeted/tailored tobacco prevention and cessation interventions for minority adolescents. Nicotine Tob Res. 2012;14(12):1394-1406.

14. Maziak W, Eissenberg T, Klesges RC, Keil U, Ward K. Adapting smoking cessation interventions for developing countries: A model for the middle east. Int J Tuberc Lung Dis. 2004;8(4):403-413.

15. Okoli C, Greaves L, Fagyas V. Sex differences in smoking initiation among children and adolescents. Public Health. 2013;127(1):3-10.

16. Wade B, Lariscy JT, Hummer RA. Racial/ethnic and nativity patterns of U.S. adolescent and young adult smoking. Population Research and Policy Review. 2013;32(3):353-371.

17. Maziak W, Nakkash R, Bahelah R, Husseini A, Fanous N, Eissenberg T. Tobacco in the Arab world: Old and new epidemics amidst policy paralysis. Health Policy Plan. 2013.

18. Maziak W. The waterpipe: A new global threat to CV health? Global Heart. 2012;7(2):179181.

19. Kelishadi R, Mokhtari M, Tavasoli A, et al. Determinants of tobacco use among youths in Isfahan, Iran. International Journal of Public Health. 2007;52(3):173-179.

20. McKelvey KL, Wilcox ML, Madhivanan P, Mzayek F, Khader Y, Maziak W. Time trends of cigarette and waterpipe smoking among a cohort of school children in Irbid, Jordan, 2008-11. Eur J Public Health. 2013;23(5):862-867.

21. Parna K, Usin J, Ringmets I. Cigarette and waterpipe smoking among adolescents in Estonia: HBSC survey results, 1994-2006. BMC Public Health. 2008;8(1):392.

22. Mzayek F, Khader Y, Eissenberg T, Al Ali R, Ward K, Maziak W. Patterns of water-pipe and cigarette smoking initiation in school children: Irbid longitudinal smoking study. Nicotine Tob Res. 2012;14(4):448-454.

23. Nasim A, Khader Y, Blank MD, Cobb CO, Eissenberg T. Trends in alternative tobacco use among light, moderate, and heavy smokers in adolescence, 1999-2009. Addict Behav. 2012;37(7):866-870.

24. Amos A, Greaves L, Nichter M, Bloch M. Women and tobacco: A call for including gender in tobacco control research, policy and practice. Tobacco Control. 2012;21(2):236-243.

25. Prokhorov AV, Winickoff JP, Ahluwalia JS, et al. Youth tobacco use: A global perspective for child health care clinicians. Pediatrics. 2006;118(3):e890-e903.

26. Warren CW, Riley L, Asma S, et al. Tobacco use by youth: A surveillance report from the global youth tobacco survey project. Bull World Health Organ. 2000;78(7):868-876. 
27. Sussman S, Skara S, Ames SL. Substance abuse among adolescents. Subst Use Misuse. 2008;43(12-13):1802-1828.

28. Petraitis J, Flay BR, Miller TQ. Reviewing theories of adolescent substance use: Organizing pieces in the puzzle. Psychol Bull. 1995;117(1):67.

29. Turner L, Mermelstein R, Flay B. Individual and contextual influences on adolescent smoking. Ann N Y Acad Sci. 2004;1021(1):175-197.

30. Wilcox P. An ecological approach to understanding youth smoking trajectories: Problems and prospects. Addiction. 2003;98:57-77.

31. Ennett ST, Foshee VA, Bauman KE, et al. A social contextual analysis of youth cigarette smoking development. Nicotine Tob Res. 2010;12(9):950-962.

32. Chang F, Lee C, Lai H, Chiang J, Lee P, Chen W. Social influences and self-efficacy as predictors of youth smoking initiation and cessation: A 3-year longitudinal study of vocational high school students in taiwan. Addiction. 2006;101(11):1645-1655.

33. de Vries H, Backbier E, Kok G, Dijkstra M. The impact of social influences in the context of attitude, self-efficacy, intention, and previous behavior as predictors of smoking onset. J Appl SoC Psychol. 1995;25(3):237-257.

34. Grucza, RA, Plunk, AD, Hipp PR, et al. Long-term effects of laws governing youth access to tobacco. Am J Public Health. 2013;103(8):1493-1499.

35. Hoving C, Reubsaet A, de Vries H. Predictors of smoking stage transitions for adolescent boys and girls. Prev Med. 2007;44(6):485-489.

36. Lando HA, Hipple BJ, Muramoto M, et al. Tobacco control and children: An international perspective. Pediatric allergy, immunology, and pulmonology. 2010;23(2):99-103.

37. Lando HA, Borrelli B, Klein LC, et al. The landscape in global tobacco control research: A guide to gaining a foothold. Am J Public Health. 2005;95(6):939-945.

38. Latimer W, Zur J. Epidemiologic trends of adolescent use of alcohol, tobacco, and other drugs. Child Adolesc Psychiatr Clin N Am. 2010;19(3):451-464.

39. Lee G, Lee J, Lee S. Risk factors of future smoking among thai youth: A secondary analysis of the Thai global youth tobacco survey. Asia Pac J Public Health. 2013.

40. Ma H, Unger JB, Chou C, et al. Risk factors for adolescent smoking in urban and rural China: Findings from the China seven cities study. Addict Behav. 2008;33(8):1081-1085.

41. Mamudu HM, Veeranki SP, John RM. Tobacco use among school-going adolescents (11-17 years) in Ghana. Nicotine Tob Res. 2013;15(8):1355-1364. 
42. Mzayek F, Khader Y, Eissenberg T, Ward K, Maziak W. Design, baseline results of Irbid longitudinal, school-based smoking study. Am J Health Behav. 2011;35(6):746-755.

43. World Health Organization. Guidelines for controlling and monitoring the tobacco epidemic. Geneva: WHO. 1998;200.

44. Maziak W, Ward K, Afifi Soweid RA, Eissenberg T. Standardizing questionnaire items for the assessment of waterpipe tobacco use in epidemiological studies. Public Health. 2005;119(5):400-404.

45. Maziak W, Rastam S, Eissenberg T, et al. Gender and smoking status-based analysis of views regarding waterpipe and cigarette smoking in Aleppo, Syria. Prev Med. 2004;38(4):479-484.

46. Maziak W, Asfar T. Physical abuse in low-income women in Aleppo, Syria. Health Care Women Int. 2003;24(4):313-326.

47. Austin SB, Gortmaker SL. Dieting and smoking initiation in early adolescent girls and boys: A prospective study. Am J Public Health. 2001;91(3):446-50.

48. Babar AA, Stigler MH, Perry CL, Arora M, Shrivastav R, Reddy KS. Tobacco-use psychosocial risk profiles of girls and boys in urban India: Implications for gender-specific tobacco intervention development. Nicotine Tob Res. 2010;12(1):29-36.

49. Trudeau L, Spoth R, Randall GK, Azevedo K. Longitudinal effects of a universal familyfocused intervention on growth patterns of adolescent internalizing symptoms and poly-substance use: Gender comparisons. Journal of Youth and Adolescence. 2007;36(6):725-740.

50. Greaves L. Gender, equity and tobacco control. Health Sociology Review. 2007;16(2):115129.

51. Zhu BP, Liu M, Shelton D, Liu S, Giovino GA. Cigarette smoking and its risk factors among elementary school students in Beijing. Am J Public Health. 1996;86(3):368-375.

52. Nichter M. Smoking: What does culture have to do with it? Addiction. 2003;98(s1):139-145.

53. Rice VH, Weglicki LS, Templin TN, Jamil H, Hammad A. Intervention effects on tobacco use in Arab and non-Arab American adolescents. Addict Behav. 2010;35(1):46-48.

54. DeCoster J, Iselin AR, Gallucci M. A conceptual and empirical examination of justifications for dichotomization. Psychol Methods. 2009;14(4):349.

55. Hosmer DW, Lemeshow S. Applied logistic regression . 2nd ed. John Wiley and Sons, Inc.; 2000 .

56. Weglicki LS, Templin TN, Rice VH, Jamil H, Hammad A. Comparison of cigarette and water-pipe smoking by Arab and Non-Arab-American youth. Am J Prev Med. 2008;35(4):334339. 
57. Roskin J, Aveyard P. Canadian and English students' beliefs about waterpipe smoking: A qualitative study. BMC Public Health. 2009;9(1):10.

58. Rice VH, Weglicki LS, Templin T, Hammad A, Jamil H, Kulwicki A. Predictors of Arab American adolescent tobacco use. Merrill Palmer Q (Wayne State Univ Press). 2006;52(2):327342.

59. Kassim S, Al-Bakri A, al'Absi M, Croucher R. Waterpipe tobacco dependence in U.K. male adult residents: A cross-sectional study. Nicotine Tob Res. 2013.

60. Rastam S, Eissenberg T, Ibrahim I, Ward K, Khalil R, Maziak W. Comparative analysis of waterpipe and cigarette suppression of abstinence and craving symptoms. Addict Behav. 2011;36(5):555-559.

61. Maziak W. The waterpipe: A new way of hooking youth on tobacco. Am J Addict. 2013;23(2):103-107.

62. Maziak W, Ward K, Afifi Soweid RA, Eissenberg T. Tobacco smoking using a waterpipe: A re-emerging strain in a global epidemic. Tob Control. 2004;13(4):327-333.

63. Maziak W. The waterpipe: Time for action. Addiction. 2008;103(11):1763-1767.

64. Maziak W. The global epidemic of waterpipe smoking. Addict Behav. 2011;36(1-2):1-5.

65. Backinger CL, Fagan P, Matthews E, Grana R. Adolescent and young adult tobacco prevention and cessation: Current status and future directions. Tob Control. 2003;12 Suppl 4:IV46-53.

66. Mitschke DB, Matsunaga DS, Loebl K, Tatafu E, Robinett H. Multi-ethnic adolescents' attitudes toward smoking: A focus group analysis. Am J Health Promotion. 2008;22(6):393-399.

67. Vitória PD, Salgueiro MF, Silva SA, de Vries H. Social influence, intention to smoke, and adolescent smoking behaviour longitudinal relations. Brit J Health Psychol. 2011;16(4):779-798.

68. Skara S, Sussman S, Dent CW. Predicting regular cigarette use among continuation high school students. Am J Health Behav. 2001;25(2):147-156.

69. Stanton WR, Barnett AG, Silva PA. Adolescents' intentions to smoke as a predictor of smoking. Prev Med. 2005;40(2):221-226.

70. Hill AJ, Boudreau F, Amyot É, Déry D, Godin G. Predicting the stages of smoking acquisition according to the theory of planned behavior. Journal of adolescent health. 1997;21(2):107-115.

71. Moyer VA. Primary care interventions to prevent tobacco use in children and adolescents: U.S. preventive services task force recommendation statement. Pediatrics. 2013;132(3):560-565. 
72. Sims TH, Committee on Substance Abuse. From the American academy of pediatrics: Technical report--tobacco as a substance of abuse. Pediatrics. 2009;124(5):e1045-53.

73. Bidstrup PE, Frederiksen K, Siersma V, et al. Social-cognitive and school factors in initiation of smoking among adolescents: A prospective cohort study. Cancer Epidemiol Biomark Prev. 2009;18(2):384-392.

74. Hiemstra M, Otten R, de Leeuw RNH, van Schayck OCP, Engels R. The changing role of self-efficacy in adolescent smoking initiation. J Adolescent Health. 2011;48(6):597-603.

75. O'Loughlin JL, Karp I, Koulis T, Paradis G, DiFranza J. Determinants of first puff and daily cigarette smoking in adolescents. Am J Epidemiol. 2009;170(5):585-597.

76. Piko BF, Luszczynska A, Gibbons FX, Mert Teközel. A culture-based study of personal and social influences of adolescent smoking. Eur J Public Health. 2005;15(4):393-8.

77. Scal P, Ireland M, Borowsky I. Smoking among American adolescents: A risk and protective factor analysis. J Community Health. 2003;28(2):79-97.

78. Tyas SL, Pederson LL. Psychosocial factors related to adolescent smoking: A critical review of the literature. Tob Control. 1998;7(4):409-420.

79. Mayhew KP, Flay BR, Mott JA. Stages in the development of adolescent smoking. Drug Alcohol Depend. 2000;59:61-81.

80. Brechwald WA, Prinstein MJ. Beyond homophily: A decade of advances in understanding peer influence processes. J Res Adolesc. 2011;21(1):166-179.

81. Wakefield M, Flay B, Nichter M, Giovino G. Role of the media in influencing trajectories of youth smoking. Addiction. 2003;98(s1):79-103.

82. White V, Webster B, Wakefield M. Do graphic health warning labels have an impact on adolescents' smoking-related beliefs and behaviours? Addiction. 2008;103(9):1562-1571.

83. Biener L, Ji M, Gilpin EA, Albers AB. The impact of emotional tone, message, and broadcast parameters in youth anti-smoking advertisements. J Health Commun. 2004;9(3):259-274.

84. Terry-McElrath Y, Wakefield M, Ruel E, et al. The effect of antismoking advertisement executional characteristics on youth comprehension, appraisal, recall, and engagement. $J$ Health Commun. 2005;10(2):127-143.

85. Biener L, Ji M, Gilpin EA, Albers AB. The impact of emotional tone, message, and broadcast parameters in youth anti-smoking advertisements. J Health Commun. 2004;9(3):259-274.

86. Jackson SF, Perkins F, Khandor E, Cordwell L, Hamann S, Buasai S. Integrated health promotion strategies: A contribution to tackling current and future health challenges. Health Promotion International. 2006;21(suppl 1):75-83. 
87. Brener ND, Billy JO, Grady WR. Assessment of factors affecting the validity of self-reported health-risk behavior among adolescents: Evidence from the scientific literature. J Adolescent health. 2003;33(6):436-457.

88. Maziak W, Mzayek F. Characterization of the smoking habit among high school students in Syria. Eur J Epidemiol. 2000;16(12):1169-1176. 


\section{Conclusion}

Smoking continues to be major preventable cause of death worldwide. As smoking rates are decreasing in developed countries, they are increasing in other parts of the world including Jordan and other countries in the EMR. In the EMR, the growing epidemic of tobacco use is partly related to a resurgence of WP use. As the first longitudinal survey of tobacco use in adolescents conducted in the EMR, this research provides critical information regarding the patterns of cigarette and WP use as well as determinants of initiation in this population. This information can be used to plan prevention and cessation interventions, as well as monitor the effectiveness of tobacco control policies. Thus, this research is important scientifically in terms

of understanding youth smoking behavior, building regional capacity in longitudinal studies, and helping to curb the ongoing smoking epidemic in Jordan and the EMR.

Across the three analyses, we found intensive smoking patterns at early ages, characterized by a predominance of WP smoking and a steeper age-related increase in cigarette smoking over the four-year period. There was a sizeable incidence of cigarette and WP initiation among students of both sexes. WP was found to be an important method of introducing youth to tobacco, as well as a vehicle for tobacco dependence and cigarette smoking. While any form of tobacco use is potentially addictive and may result in dangerous health consequences, cigarette smoking may be the most harmful due to its portability and accessibility, leading to more frequent use. In addition, the powerful influence of smoking by other important people in youths' lives was observed to significantly impact WP and cigarette initiation in these studies.

The first study showed intensive smoking patterns at early ages, characterized by a predominance of WP smoking but a steeper increase in cigarette smoking. These findings suggest that more attention should be paid to WP smoking at early ages as part of an overall tobacco control strategy among youth in Irbid. The time-trends noticed in this study lead to very valuable research questions aimed at understanding gender- and administration method- specific tobacco 
use and addiction research among youth in Irbid, Jordan, and the Middle East. Outcomes of this study also indicate a need for tobacco prevention programming designed to reach children as young as age 8 .

The investigation into determinants of WP initiation found that adolescents' efficacy to resist invitations to smoke and clear intention to start smoking were important factors associated with beginning to smoke WP. The influence of smoking by siblings, teachers, and friends were also predictive of WP initiation among youth in this study. Together these findings provide support for the development and implementation of "social influence" smoking prevention type interventions focused on enhancing the skills needed to resist social pressure to begin smoking WP. The influence of prior cigarette smoking on actual WP initiation, along with the mean initiation age (14 years) of this cohort, suggests that interventions need to begin early, ideally target youth who have not yet smoked, and address both forms of tobacco use.

Results from the study on determinants of cigarette smoking initiation suggest that multiple levels of influence are involved in cigarette initiation and that individual and social level variables are important in contributing to the onset of smoking among Jordanian adolescents. Girls were more strongly influenced by family members' smoking, indicating that prevention efforts geared toward girls should encourage smoking cessation for families and help parents communicate strong antismoking norms to their children. Further, as also found in the WP initiation study, the role of WP smoking in the initiation of cigarettes is evident. Again, it is important to include information about the harmful effects of WP and WP cessation counseling in future tobacco control programs.

Overall, these results provide new insights into potentially modifiable risk factors for cigarette intiation among adolescents in Jordan that can be used to explore smoking initiation in other developing countries. Going forward continued monitoring of youth smoking trends and further evaluation of gender-specific risk and protective factors for initiation of cigarette and WP 
are suggested avenues of investigation and could provide clear direction for smoking prevention interventions. Early cigarette and WP smoking prevention interventions should exploit the power of modeling by peers and family members and should help to build smoking refusal skills. Finally, strong anti-smoking policies must be implemented and enforced to reduce the amount of exposure to smoking behavior modeled by adults and to reduce access to tobacco by children. Changing community norms from pro- to anti-smoking requires time, resources, and a sound evidence base. We hope that the dissemination of our research findings and outcomes from future smoking studies in the EMR will help to move anti-smoking efforts forward in this region of the world. 
VITA

KARMA L. MCKELVEY, PhD

Born, Las Vegas, Nevada

B.S., Anthropology - summa cum laude

Florida International University

Miami, Florida

1997-2007

Paralegal

Miami, Florida

2007-2009

Yoga teacher training

Nasik, Maharashtra, India

2009-2011

Graduate teaching assistant

Florida International University

Miami, Florida

2011

MPH, Epidemiology \& Biostatistics

Florida International University

Miami, Florida

2012-2014

Graduate research assistant

Florida International University

Miami, Florida

2013-2014

Doctoral Candidate

Florida International University

Miami, Florida

\section{PUBLICATIONS AND PRESENTATIONS}

Abdel-Hamid T, Akshay VS, Ankel F, Battle-Fisher M, Gibson B, Gonzalez-Parra G, Jalali MS, Daipainen K, Kalupahana NS, Karanfil O, Marathe A, Martinson BC, Murphy PJ, McKelvey K, van Oorschot K, Pintauro S, Poucheret P, Pronk N, Qian Y, Sarbadhikari N, Sazonov E. (2013) Public and Health-Professionals' Misconceptions about Dynamics of Weight Gain/Loss. Syst Dynam Rev (In Press).

FIU - Epidemiology Journal Club Classic Readings in Epidemiology

- $\quad$ Sick Individuals \& Sick Populations 2011

McKelvey K, Wilcox M, Madhivanan P, Mzayek F, Khader, Maziak W. Time-trends of cigarette and WP smoking among a cohort of school children in Irbid, Jordan 2008-2011. 2013. Eur J Public Health; 23(5):862-867. doi: 10.1093/eurpub/ckt140 
McKelvey, K., Attonito, J., Madhivanan, P., Jaber, R., Yi, Q., Mzayek, F., \& Maziak, W. Determinants of waterpipe smoking initiation among school children in Irbid, Jordan: a 4-year longitudinal analysis. 2014. Drug Alcohol Depend. doi: 10.1016/j.drugalcdep.2014.06.038

Pavlova-McCalla, E; Trepka, MJ; Ramirez, G; Niyonsenga, T. Socioeconomic status and survival of people with human immunodeficiency virus infection before and after the introduction of highly active antiretroviral therapy: A systematic literature review. J AIDS Clin Res; 2012; $3(6)$.

Risk factors for cigarette smoking initiation among Jordanian adolescents: a longitudinal analysis. Karma McKelvey. Presented at International Symposium of Social Determinants of Non-communicable Disease, Istanbul, Turkey, May 7, 2013.

Small Group Behavioral Health Interventions Reduce Distress among HIV-positive Recovering Drug Abusers (RDA's). Neha Desai, MPH, Shyam Jindal, MPH, Karma Scott, BS, Yamile Marrero,JD,MPH, Brenda Lerner, PsyD, Jessy Devieux, PhD, and Robert Malow, Ph.D. Presented at APHA, Philadelphia, PA, November 7-11, 2009.

Time-trends of cigarette and WP smoking among a cohort of school children in Irbid, Jordan 2008-2011. K. McKelvey, M. Wilcox, P. Madhivanan, Fawaz Mzayek, Y. Khader, W. Maziak. Presented at International Symposium of Social Determinants of Non-communicable Diseases, Istanbul, Turkey, May 6-7, 2013. 